\title{
La construcción de conceptos en Cinemática a través de la argumentación y la activación de actitudes en formación inicial de maestros
}

\author{
Beatriz Pérez-Bueno ${ }^{1}$, María Ángeles de las Heras Pérez², Roque Jiménez-Pérez ${ }^{2}$ \\ ${ }^{1}$ Centro de Estudios Universitarios Cardenal Spínola CEU, Dpto. Ciencias Experimentales

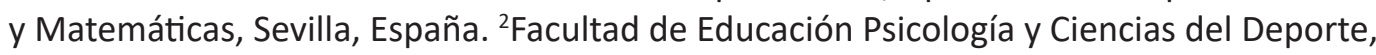 \\ Departamento de Didácticas Integradas, Universidad de Huelva, España
}

[Recibido el 10 de octubre de 2018, aceptado el 26 de abril de 2019]

\begin{abstract}
Se pretende comprobar si un proceso de enseñanza y aprendizaje basado en la argumentación durante la resolución de problemas provoca un cambio positivo en ciertas actitudes del alumnado hacia la Ciencia, su aprendizaje y su didáctica. Se eligió intencionadamente la "Cinemática", pues su estudio reúne ciertas características: la fácil contextualización y las relaciones proporcionales que se establecen entre las magnitudes implicadas. La recogida de datos se realizó a través de un cuestionario Likert y un pre y post-test que se analizaron a través de una tabla de categorías. Participaron 65 alumnos del segundo curso del Grado de Educación Primaria del Centro de Estudios Universitarios Cardenal Spínola CEU. Tras el análisis de los datos, pudimos apreciar una mejora en las tres componentes en las que dividimos las actitudes (cognitiva, afectiva y conductual) llevándonos a la reflexión de la importancia de romper con los métodos de enseñanza tradicionales para dar paso a nuevas estrategias que inviten a la reflexión y el diálogo en las aulas.
\end{abstract}

Palabras clave: formación Inicial de maestros; actitudes; argumentación; competencia científica; resolución de problemas.

\section{The construction of the concept of kinematics through an argumentation and attitude activation in initial teacher training}

This study aims to verify whether a argumentation based teaching and learning process during the resolution of kinematics problems could cause a positive change in certain attitudes of students towards science, it learning and it didactics while they are aware of their processes and develop skills that favor more critical learning. The "Kinematics" was intentionally chosen, since its study has certain characteristics: the easy contextualization of problematic situations and the proportional relationships established between the magnitudes involved. The data collection was done through a Likert questionnaire and a pre and post-test, which were analysed through a table of categories. A single experimental group was selected, consisting of 65 teacher trainees in their second year of studies at Cardenal Spínola CEU Study Center. The data from the analysis show an improvement in all three components (cognitive, affective and behavioral). This, therefore, leads us to appreciate the importance of breaking with traditional teaching methods in favour of new strategies that foster discussion in classrooms.

Keywords: initial teacher training; attitudes; argumentation; scientific competence; problem solving.

Para citar el artículo. Pérez-Bueno, B., De las Heras, M.A. y Jiménez-Pérez, R. (2020). La construcción de conceptos en Cinemática a través de la argumentación y la activación de actitudes en formación inicial de maestros. Ápice. Revista de Educación Científica, 4(1), 35-62. DOI: https://doi. org/10.17979/arec.2020.4.1.4584

Contacto. beatriz.perez.bueno@gmail.com, angeles.delasheras@ddcc.uhu.es, rjimenez@uhu.es 


\section{Introducción}

Vivimos rodeados por múltiples fuentes informativas, lo que supone que tengamos a nuestra disposición una abundante, quizás excesiva, y diversa información. Además, se ha puesto de manifiesto que, aunque la sociedad es cada vez más tecnológica, el desinterés por la Ciencia y la Tecnología se hacen también más visibles (Martínez-Artero y De Pro, 2003). Esto ha hecho que la meta final de la educación científica haya evolucionado desde una casi exclusiva preparación propedéutica, a una formación de personas capaces de participar en una sociedad cambiante, de dar coherencia a todos los estímulos recibidos para poder evaluar e integrar la información y de ser consciente de la presencia de la Ciencia en sus vidas (Márquez Bargalló, 2011).

Para conseguir este objetivo la OCDE (2002) propuso, a través del informe DeSeCo (Desing and Selection of Competencies), un currículo competencial. Una de las competencias básicas contempladas en el Real Decreto 126/2014, de 28 de febrero, por el que se establece el currículo básico de la Educación Primaria en España, es la denominada Competencia matemática y competencias básicas en ciencia y tecnología, mediante la que se pretende que los estudiantes, no solo dispongan de los conocimientos y procedimientos científicos y tecnológicos necesarios para desenvolverse en la vida diaria, sino además de una formación en actitudes positivas y fundamentadas hacia la Ciencia que contribuyan a dar sentido a los conocimientos adquiridos (Robles, Solbes, Cantó y Lozano, 2015).

Sin embargo, aún se está lejos de cambiar la actividad que se realiza en el interior de las aulas debido, por un lado, a la poca formación del profesorado en esta nueva visión de la educación científica (Vázquez y Manassero, 2016) y, por otro lado, a sus limitaciones en conocimientos y destrezas cognitivas, a la imagen distorsionada que tienen de la Ciencia y a la falta de autoestima y confianza para conseguir el éxito en asignaturas enfocadas al conocimiento científico y su didáctica (García-Ruiz y Orozco, 2008).

Reflexionando sobre qué características deben tener los programas de formación docente para favorecer el logro del desarrollo de competencias científicas y un cambio en las actitudes inmersas en su cocimiento didáctico del contenido (CDC) (Shulman, 1986), señalamos la argumentación como parte esencial de su formación (Archila, 2012). Una práctica basada en la reflexión de los estudiantes y en la toma de conciencia sobre sus ideas durante la resolución de problemas científicos, necesariamente, los implicará en la comprensión de sus propios procesos de aprendizaje y en la forma en que estructurarán sus conocimientos y algoritmos (McDermott, 1998). De esta manera, lograrán comprender los conceptos que subyacen en la situación planteada (Guirado, Mazzitelli y Maturano, 2013) facilitando, además, un cambio en las creencias, emociones y expectativas hacia la materia y a valorar las Ciencias por su contenido.

Para poder llevar a cabo esta estrategia de aprendizaje y enseñanza se escogió, intencionadamente, el tópico de la Cinemática, pues su estudio reúne ciertas características que ayudan a alcanzar los objetivos de esta investigación: por un lado, la fácil contextualización de situaciones problemáticas $y$, por otro, las relaciones proporcionales que se establecen entre las magnitudes implicadas en movimientos uniformes. Se considera necesario que el alumnado construya y asimile, a partir de su significado, los conceptos de posición, velocidad y aceleración, los cuales constituyen la columna vertebral en el análisis de situaciones que involucran el movimiento. 


\section{Marco Teórico}

\section{Las actitudes como parte de un currículo competencial}

Analizando las distintas reformas curriculares que se han estado produciendo desde los años noventa, se observa que han buscado distanciarse de una enseñanza basada únicamente en aspectos meramente cognitivos, introduciendo aspectos más sociales y personales del propio estudiante. La primera reforma que introdujo un nuevo planteamiento fue la LOGSE, que distinguió claramente los contenidos en tres dimensiones complementarias: conceptuales, procedimentales y actitudinales. Esto es, se apostó por un enfoque más constructivista centrado en el proceso y no tanto en los conceptos y, como gran innovación, se introdujeron las actitudes como un contenido independiente. Especial interés reviste la inclusión de las competencias básicas entre los componentes del currículo en la LOE, traídas a su vez del Informe DeSeCo (OCDE, 2002), considerándolas como combinación de conocimientos, habilidades prácticas, actitudes, y otras componentes sociales que se movilizan para lograr una realización personal.

Se ha de poner de manifiesto, dependiendo del interés del autor, la polisemia del término actitud en el campo de la psicología o de la psicopedagogía. En nuestro caso, tal y como consideraron García-Ruiz y Sánchez-Hernández (2006), asumimos que una actitud implica tanto constructos cognitivos como afectivos y conductuales, ya que se considera que un proceso de enseñanza y aprendizaje realista debe favorecer la integración de las tres componentes -Componente cognitiva": convicciones o creencias. "Componente afectiva": sentimientos, emociones y estados de ánimo. "Componente conductual": declaraciones de intenciones- tratándolas al mismo nivel.

Por un lado, se considera necesario estudiar las creencias y convicciones que tienen los profesores en formación inicial sobre la Ciencia y su didáctica. Por otro lado, Mora (2016) afirma que, para promover el gusto por las Ciencias, el docente debe buscar emociones positivas asociadas al aprendizaje de las mismas. Para ello, se han de utilizar estrategias de aprendizaje adecuadas, mostrando una Ciencia más dinámica y cercana a las realidades del alumnado, mejorando las actitudes afectivas hacia ella y, con ello, buscando una satisfacción personal.

Vivimos en una cultura que ha infravalorado las emociones y sobrevalorado la razón. Sin embargo, el lado emocional reporta una gran influencia sobre la elaboración de una gran cantidad de constructos tales como, la motivación (Mora, 2016), el autoconcepto y la autoeficacia (Brígido y Borrachero, 2011), así como la inteligencia emocional (Goleman, 1996), que actúan como motores que impulsan la construcción del conocimiento científico.

Por otro lado, como dice Maturana (2001): "no hay acción humana sin una emoción que la fundamente como tal y la haga posible como acto" (p. 13). Consecuentemente, no se debe olvidar que las dimensiones afectiva y conductual juegan un papel muy importante en el desarrollo profesional del profesorado, debiendo formar parte de su conocimiento personal y práctico y de su CDC (Mellado, Garritz y Brígido, 2009).

\section{La argumentación como parte de la componente científica}

Referirnos a la argumentación como parte de la competencia científica, es aceptar la importancia del uso de la comunicación y el lenguaje en la construcción del conocimiento científico.

La importancia que tiene un aprendizaje basado en la argumentación, es decir, en el diálogo y en la reflexión sobre las propias ideas, es que el estudiante se implica en la comprensión, cimentación y estructuración de sus conocimientos, favoreciendo la rectificación 
de sus propias imágenes y percepciones sobre la ciencia y sobre los conceptos científicos, Ilenándolos de significado. Custodio, Sanmartí y Márquez Bargalló (2015) lo expresan diciendo que si un estudiante es capaz de construir un argumento científico coherente y preciso significa que ha comprendido los conceptos y es capaz de relacionarlos y aplicarlos en el caso concreto que se le plantea y en otros cuyo contexto lo permita. Esto nos hace considerar la argumentación como parte de la competencia científica.

\section{La resolución de problemas de Cinemática como estrategia de aprendizaje basada en la argumentación}

Tomando la argumentación como la explicitación del proceso de resolución de problemas, hemos recurrido al modelo de Toulmin (1958) (ver figura 1) para definir sus elementos más característicos entre los datos y las conclusiones, los cuales, a su vez, nos ayudaron a evaluar las argumentaciones de los alumnos según estén representados.

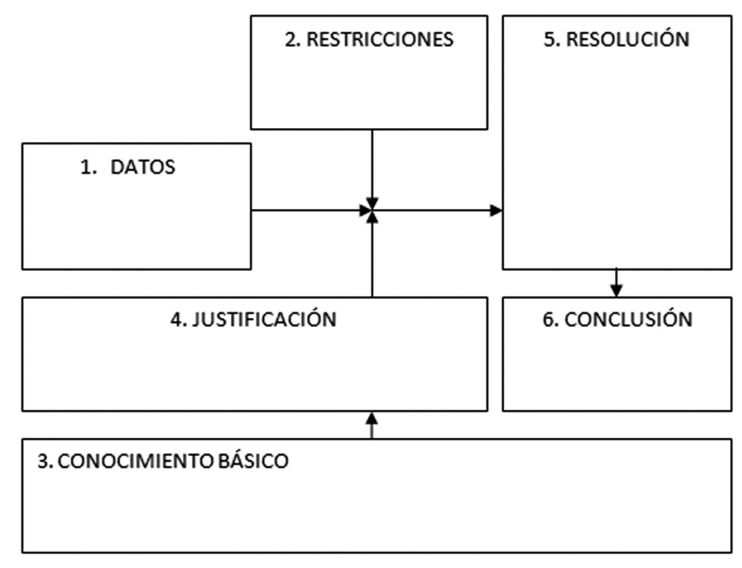

Figura 1. Adaptación propia del Modelo de Toulmin (1958)

Resultados de investigaciones como la de Bravo, Puig y Jiménez-Aleixandre (2009) ponen de manifiesto las dificultades que tiene el alumnado para argumentar durante el proceso de resolución. En su lugar, dan vagas explicaciones o realizan meras descripciones sin proporcionar un mecanismo causal. Para ello, se propone trabajar modelos de resolución de problemas que reúnan las características apropiadas para promover formas complejas de razonamiento similares a las de la actividad científica. En este sentido, el estudio propuesto por García-García (2000) señala, entre otras conclusiones, que la aplicación de un tipo de estrategia de enseñanza y aprendizaje argumentativa logra cambios progresivos en los niveles de reflexión, aumentando, además, la motivación siempre que los problemas planteados sean de interés y con el grado de utilidad que el estudiante le confiera.

La elección del tópico Cinemática viene motivada por varios aspectos. Por un lado, hay una tendencia a construir los conceptos de reposo y de movimiento de manera intuitiva y por sentido común y que muchas veces no coinciden con el significado que le da la Ciencia. Incluso alumnos que inician estudios de ingeniería mantienen errores de concepto en lo relativo a las magnitudes de posición, velocidad y aceleración (Fuentes Vargas, 2016). De este modo se propone abordar la Cinemática a partir de la reflexión sobre experiencias cotidianas del alumnado, valorar si sus conocimientos previos resultan ser obstáculos a superar y estudiar qué herramientas disponen para que puedan rectificar y asimilar los fenómenos cinemáticos.

Hay que destacar, por otro lado, que los profesores en formación muestran limitaciones para afrontar situaciones de proporcionalidad entre magnitudes (Buforn y Fernández, 
2014), tanto en la resolución de problemas como en su uso en situaciones cotidianas, por lo que en este estudio se aprovechan las relaciones existentes entre las magnitudes espacio, velocidad y aceleración para trabajar este constructo matemático que soporta gran parte de las leyes de la Física (Ríordaín, Johnston y Walshe, 2015).

Tradicionalmente la Cinemática se trabaja exclusivamente a través de ecuaciones, lo que supone una simple exposición de ideas abstractas y meros desarrollos matemáticos que conllevan una repetición de procedimientos y, por tanto, a un aprendizaje memorístico. El hecho de que los estudiantes sean capaces de resolver problemas cuantitativos estandarizados no significa que hayan comprendido los fenómenos físicos sobre el movimiento que en él subyacen (Ponce, 1997). De acuerdo con McDermontt (1998), en la metodología de enseñanza que se propone, se comienza por la comprensión cualitativa y se retiene el formalismo matemático hasta que los estudiantes adquieran cierta práctica de razonamiento con relación al fenómeno estudiado.

\section{Objetivos de la investigación}

Los objetivos de esta investigación han sido establecer qué tipo de estrategia eligen los estudiantes para maestro al enfrentarse a la resolución de problemas de Cinemática, antes y después de la implementación de un proceso de enseñanza y aprendizaje basado en la argumentación, usando las unidades de medida como eje principal para la comprensión de las magnitudes involucradas y sus relaciones, estudiando, además, cómo influye esta elección en las actitudes de los alumnos hacia las Ciencias, hacia la física como asignatura y hacia la enseñanza de las Ciencias.

Podemos entender que una estrategia argumentativa, donde los estudiantes tomen conciencia de sus propias dificultades y la búsqueda de soluciones de forma autónoma, supondrá un cambio de actitud positiva de aquellos hacia la Ciencia en general, hacia la Física como asignatura y hacia la enseñanza de la Ciencia.

\section{Metodología}

Se ha optado por una metodología cuasiexperimental, descriptiva y correlacional a partir de un solo grupo experimental. Las variables estudiadas se recogen en la figura 2.

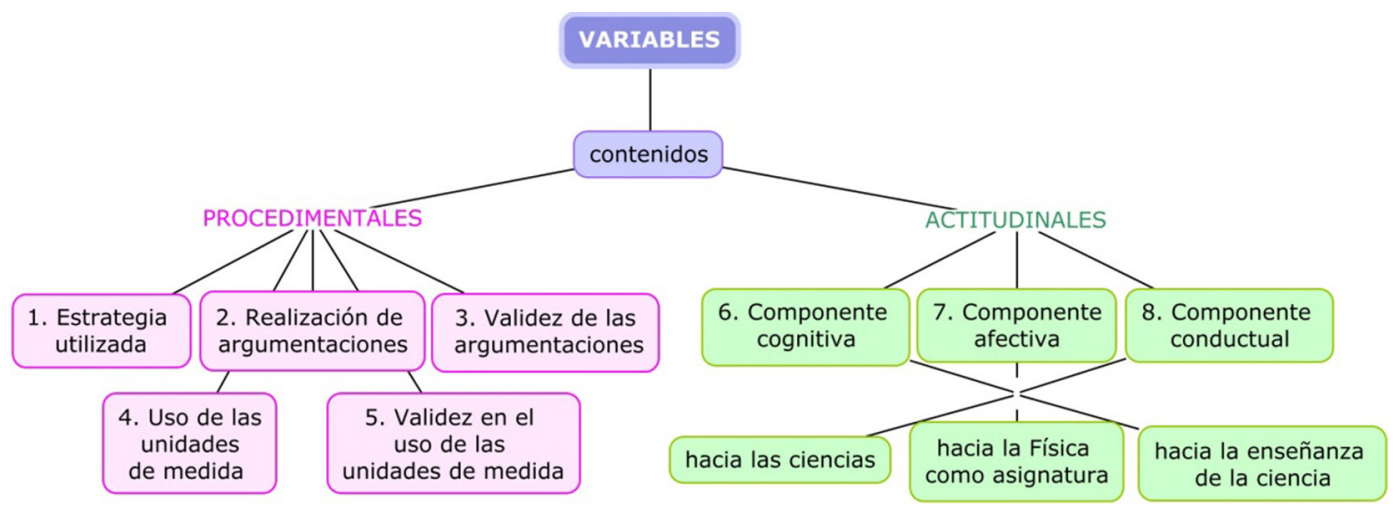

Figura 2. Variables de la investigación

\section{Contexto y muestra}

La investigación se realizó en un centro de estudios universitario privado situado en la localidad de Bormujos. La muestra circunstancial escogida de 65 alumnos formaba parte 
del segundo curso del Grado de Educación Primaria en la formación inicial de Maestros durante el curso académico 2016/2017. Cabe destacar que únicamente el 10,8\% de la muestra recibió clases de Física en 20 de Bachillerato. Este dato está acorde con estudios como el de Solbes (2011) sobre el abandono temprano de asignaturas con carácter científico.

\section{Instrumentos de recogida de datos}

Debido a la naturaleza de esta investigación se han utilizado, dos tipos de instrumentos de recogida de datos, los cuales describimos a continuación.

\section{Pre y post-test contenido procedimental}

Para el estudio de las variables correspondientes a los contenidos procedimentales, se recurrió a un pre y post-test (ver anexo 1) compuestos por actividades que se caracterizan de "lápiz y papel", con planteamientos de situaciones tanto cualitativas como cuantitativas para asegurar la flexibilidad, tanto en la estrategia del proceso de resolución, como en las argumentaciones de los alumnos.

Los test están compuestos por dos situaciones problema, uno para trabajar las magnitudes involucradas en el movimiento rectilíneo uniforme (MRU) y otro para las del movimiento rectilíneo uniformemente acelerado (MRUA). A su vez, los problemas están divididos en distintos apartados con el objetivo de facilitar la recogida de datos.

Por otro lado, en dichos test se recoge el género del alumno y el último curso que recibió la asignatura de Física, factores que podrían influir en las variables estudiadas.

\section{Cuestionario de actitudes y su validación}

Una vez elaborado un cuestionario de actitudes provisional, se procedió a la validación del mismo, por un lado, bajo el criterio de tres expertos, los cuales ayudaron a la redacción de los ítems y a la validez del contenido y, por otro, a partir de una muestra piloto de 30 alumnos que no solo contestaron al test, sino que, además, incluyeron anotaciones en aquellos enunciados que consideraron que necesitaban aclaración. Este proceso nos llevó a desarrollar el cuestionario de actitudes definitivo (ver anexo 2). La segunda muestra piloto escogida para el test definitivo fue de 25 alumnos distintos a los anteriores.

Mediante el Statistical Package for the Social Sciences (SPSS) se realizó un estudio de fiabilidad para comprobar la consistencia interna. Los valores obtenidos, tanto para el cuestionario provisional como para el definitivo, están muy por encima del 0.7, valor mínimo aceptable, aportándole una gran fiabilidad al modelo de prueba realizado (Ver tabla 1).

Tabla 1: Estadísticos de fiabilidad

\begin{tabular}{|l|c|c|c|}
\hline Alfa de Cronbach & $\begin{array}{c}\text { Componente } \\
\text { cognitiva }\end{array}$ & $\begin{array}{c}\text { Componente } \\
\text { afectiva }\end{array}$ & $\begin{array}{c}\text { Componente } \\
\text { conductual }\end{array}$ \\
\hline Test provisional & 0.973 & 0.950 & 0.940 \\
\hline Test definitivo & 0.942 & 0.918 & 0.960 \\
\hline
\end{tabular}

Además, se aplicó la técnica estadística de correlaciones bivariadas para comprobar que las cuestiones enunciadas en positivo y en negativo tenían una clara relación y ésta era lo suficientemente fuerte. Se observó que, en el caso del test provisional, existían dos casos para cada componente en los que el coeficiente de significación estaba por encima del 0.05 , lo que nos indicó que no existía relación entre las respuestas de estos dos enuncia- 
dos. Además, analizando la fuerza de correlación entre el resto de los valores, no resultaron suficientemente satisfactorios a nuestro entender, considerando como válido para ello un valor mínimo en el coeficiente de Spearman de 0.600. Sin embargo, los resultados para el test definitivo mostraron un aumento del nivel de significación y de la fuerza de correlación entre todas las cuestiones enunciadas en positivo/negativo, lo que nos hizo dar por válido el cuestionario definitivo.

\section{Instrumentos de análisis de datos}

Para el análisis del pre y post-test nos apoyamos en una tabla donde para cada variable se definieron indicadores en función de unos descriptores concretos. Éstos se presentan de forma ordenada a modo de hipótesis de progresión, con cuatro niveles bien diferenciados, que orientan sobre la evolución de las respuestas de los alumnos (ver anexo 3).

\section{Planificación didáctica}

El estudio se ha llevado a cabo durante 7 sesiones a lo largo de tres semanas. Durante todo el proceso se han trabajado los conceptos contextualizados en experiencias cotidianas donde intervienen fenómenos relacionados con la cinemática en particular y con la Ciencia en general, ya que buscamos la reflexión, no solo sobre dichos fenómenos, sino también sobre su imagen acerca de la Ciencia y su Didáctica. En el anexo 4 se muestra un ejemplo de algunas de las actividades trabajadas en clase.

- Primera sesión: Presentación del proyecto y aplicación del pre-test y del cuestionario de actitudes.

- Segunda sesión: Conceptos de proporcionalidad atendiendo, sobre todo, a la importancia de reconocer las magnitudes, tanto básicas como derivadas y las relaciones existentes entre ellas gracias a las unidades de medida.

- Tercera sesión: Introducción a los conceptos básicos de la Cinemática.

- Cuarta sesión: Movimiento Rectilíneo Uniforme.

- Quinta sesión: Movimiento Rectilíneo Uniformemente acelerado.

- Sexta sesión: Discusión y reflexión sobre los conceptos aprendidos.

- Séptima sesión: Aplicación del post-test y, nuevamente, del cuestionario de actitudes.

\section{Resultados y discusión}

\section{Contenidos procedimentales}

Lo más destacable del análisis del pre-test es que el 77\% de la muestra no fue capaz de enfrentarse a la resolución de las situaciones problemáticas planteadas, entregando el test práctica o totalmente en blanco. Si atendemos a las características de la muestra observamos que la mayor parte $(86 \%)$ de los estudiantes que respondieron son aque-

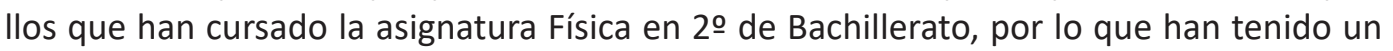
contacto más reciente con conceptos científicos y esto les ha facilitado enfrentase a los problemas planteados en el test. Sin embargo, tras la aplicación del estudio, el $95 \%$ de los alumnos sí se han sentido con suficientes herramientas cognitivas para afrontar la prueba, independientemente de la validez del proceso.

\section{Variable 1: estrategia seleccionada}

La figura 3 constata un marcado cambio en la elección de la estrategia seleccionada en el antes y en el después, apostando una mayoría por una estrategia que implica la reflexión sobre las características de las magnitudes implicadas. 

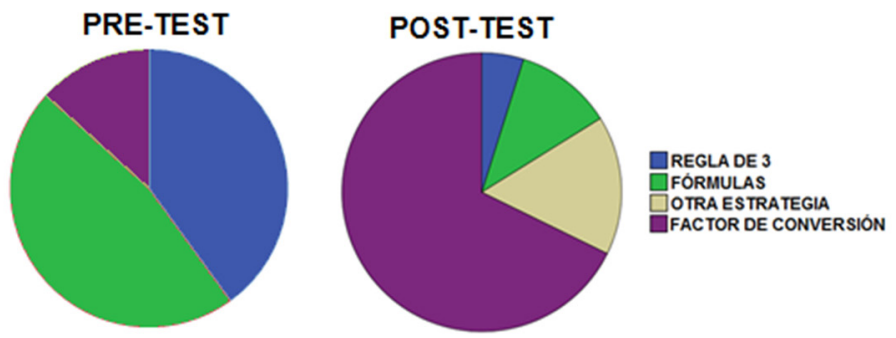

Figura 3. Diagrama de sectores comparativos de estrategias pre y post-test

Además, en el pre-test se vuelve a apreciar una clara influencia entre la elección de estrategia y el último año en que los alumnos cursaron Física, ya que el $100 \%$ de los que lo hicieron en Bachillerato optaron por el uso memorístico de fórmulas (ver figura 4), y los que la abandonaron en curso anteriores se decantaron, la mayoría de ellos, por la regla de tres. Esto no ocurre en el post-test. De esto es posible inferir que, a medida que pasa el tiempo, los alumnos olvidan las fórmulas y conceptos memorizados y no comprendidos, buscando otras vías de resolución, donde la regla de tres les parece una herramienta multiusos para cualquier contexto. Se puede hacer esta afirmación ya que algunos alumnos solo han sido capaces de aplicarla correctamente en el MRU, no así en el MRUA, dando a entender que no comprendían la relación de proporcionalidad entre las magnitudes espacio-tiempo y velocidad-tiempo. La figura 5 muestra dos ejemplos.

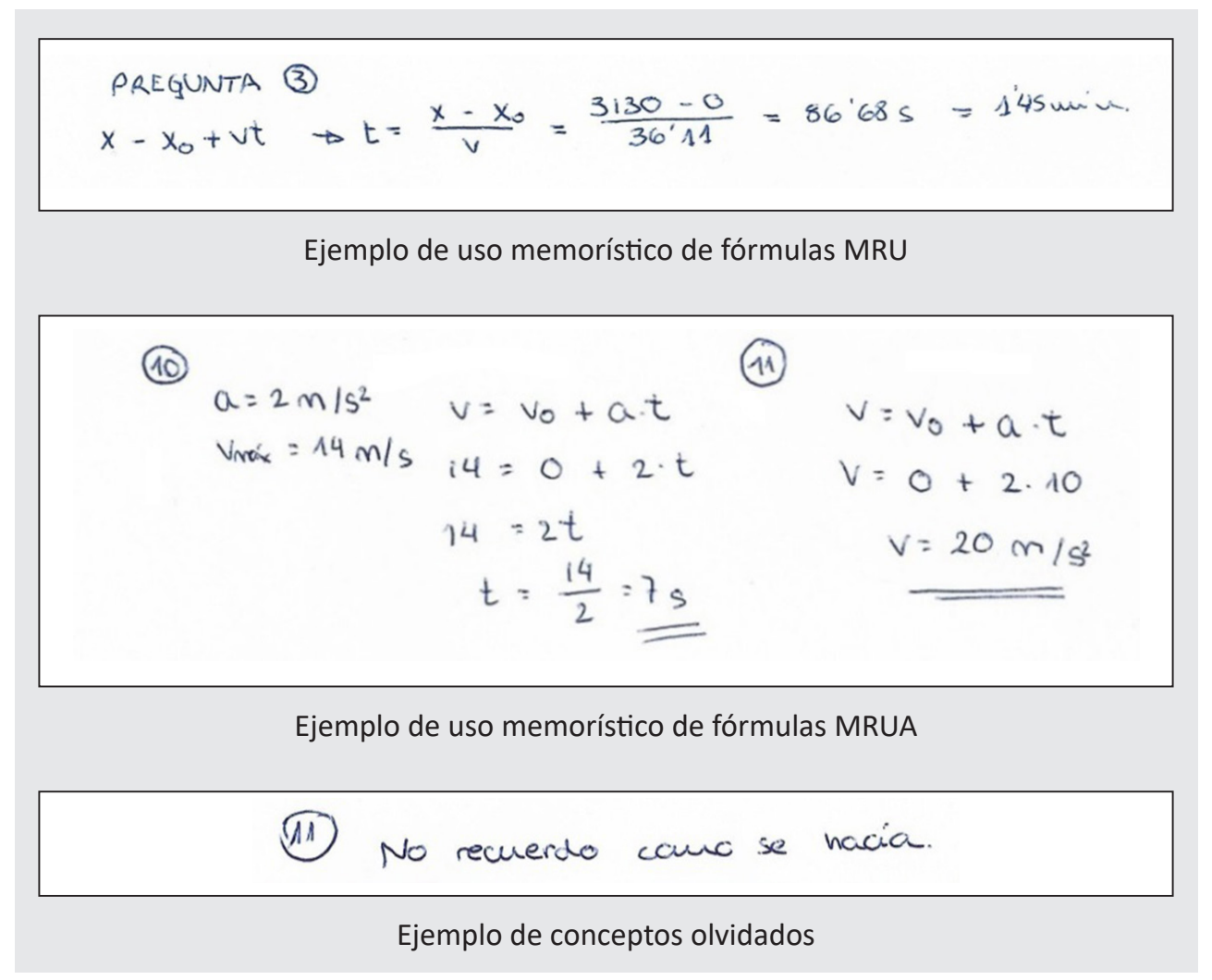

Figura 4. Ejemplos de uso memorístico de fórmulas 


$$
\begin{aligned}
& \text { 11-Nos piden que calcutemos la velocidad (m/s) } \\
& \begin{array}{l}
2 \mathrm{~m}-10 \mathrm{~s} . \\
100 \mathrm{~m}-\frac{1000}{2}=500 \mathrm{ne} / \mathrm{s} .
\end{array}
\end{aligned}
$$

Ejemplo de regla de tres en un MRUA entre magnitudes no proporcionales

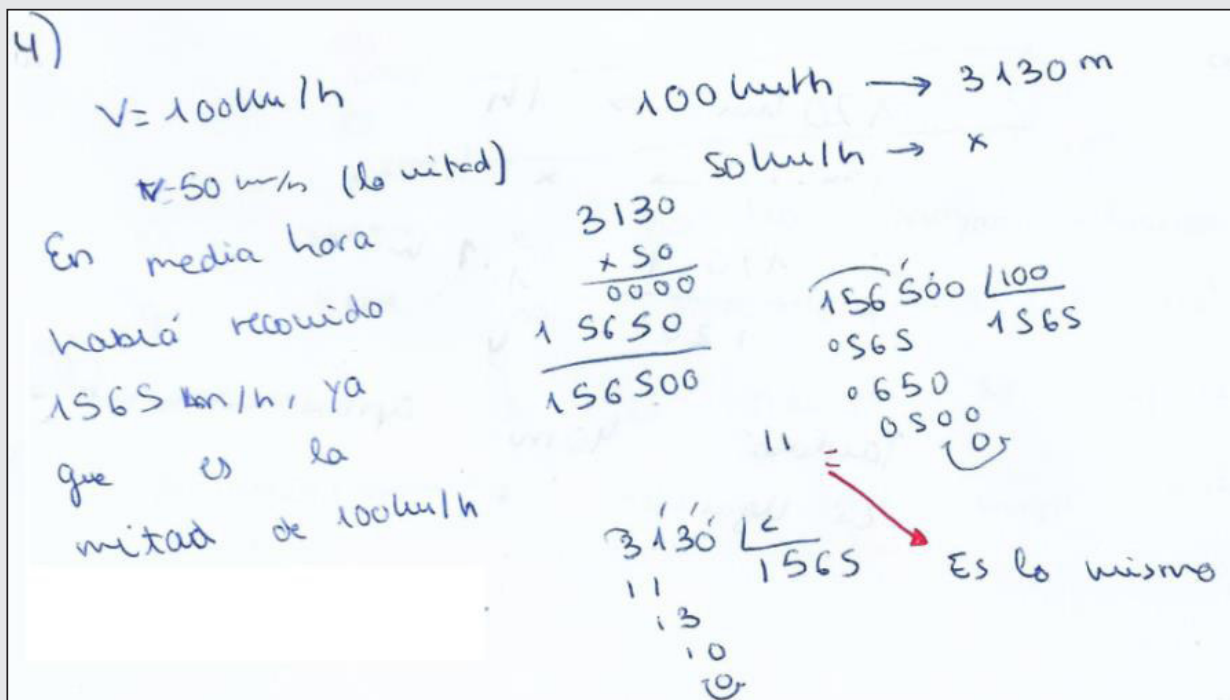

Ejemplo de regla de tres mal interpretada en un MRU

Figura 5. Ejemplos de reglas de tres mal interpretadas

\section{Variables 2 y 3: uso y validez de la argumentación}

Para aquellos alumnos que sí han respondido a los test, observamos también un cambio significativo en el antes y en el después a la hora de hacer "uso de las argumentaciones" durante el proceso de resolución de problemas (ver figura 6).

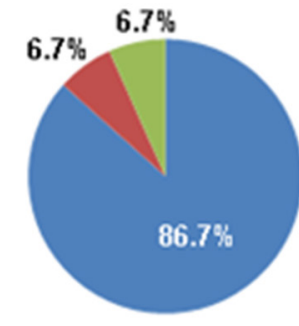

PRE-TEST

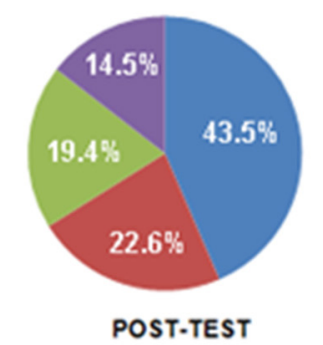

POST-TEST

Figura 6: Diagrama de sectores comparativos de uso de argumentación pre y post-test

Mientras que el $86.7 \%$ de la muestra del pre-test nunca utilizó la argumentación durante su proceso en la resolución de las actividades, en el post-test ha disminuido a menos de la mitad (43.5\%). Destacar el $14.5 \%$ de los alumnos que siempre han argumentado sus razo- 
namientos durante el desarrollo del post-test que, aunque parezca una cifra insignificante, supone un gran avance en el propósito de este estudio, pues forma parte del objetivo del mismo.

Hemos de señalar, además, que ha sido una práctica habitual la confusión de describir con argumentar. Dichas descripciones están contenidas dentro del $43.5 \%$ de alumnos que no han argumentado. Para caracterizar la validez de las argumentaciones del alumnado nos hemos basado en la existencia, explícita o implícita, de los elementos característicos para la argumentación según Toulmin (1958). (Se puede ver un ejemplo de cada una de las versiones en la figura 7)

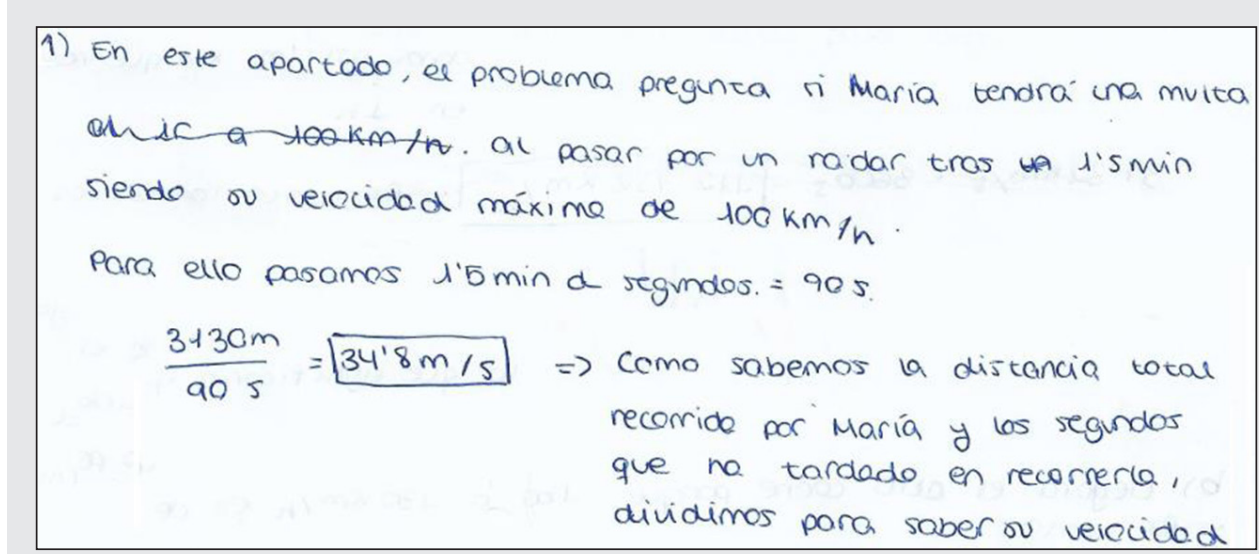

Ejemplo de descripción del proceso y no argumentación

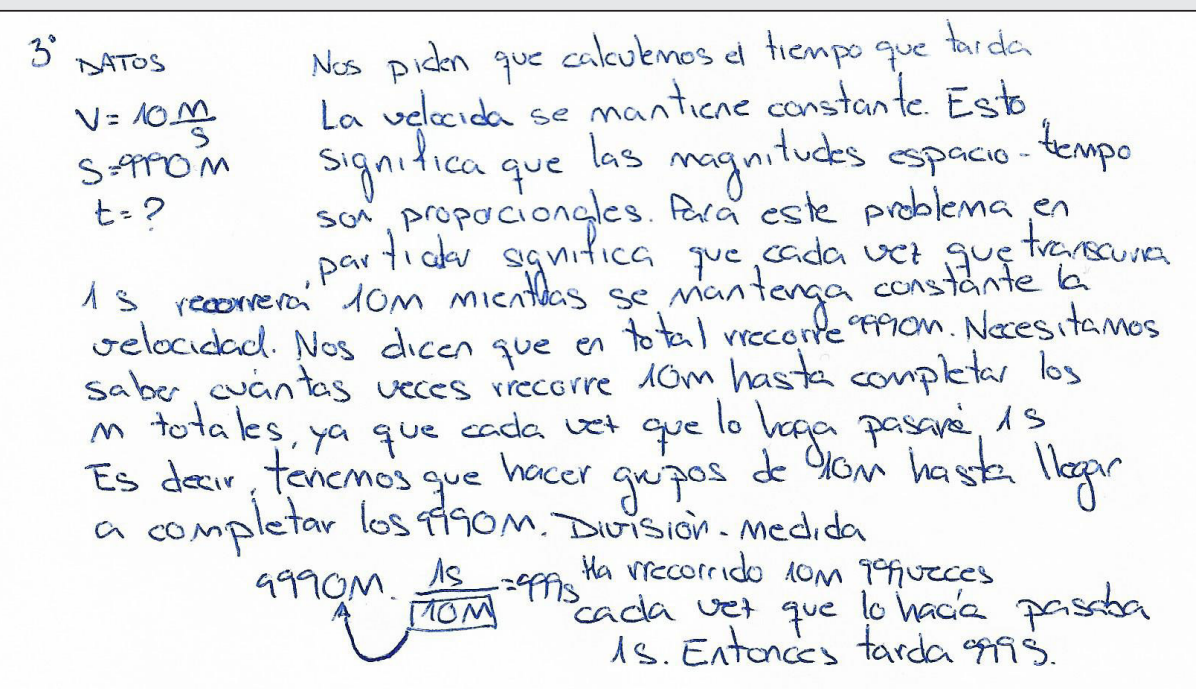

Ejemplo de uso de argumentación válida

Figura 7: Ejemplos de uso de argumentación

Los porcentajes sobre la validez de las argumentaciones para aquellos alumnos que sí las han utilizado en el post se muestran en la a figura 8. 


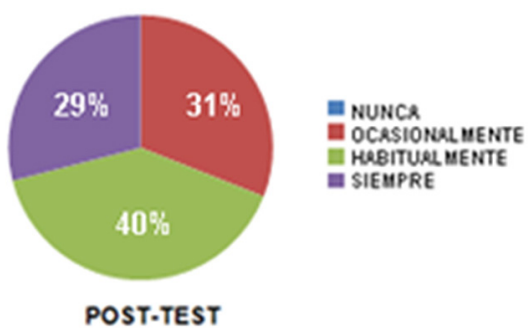

Figura 8: Diagrama de sectores para la validez de la argumentación en el post

\section{Variables 4 y 5: uso y validez de las unidades de medida}

El contraste del "uso de las unidades de medida" a lo largo del proceso de resolución de las situaciones problemáticas en el antes y en el después ha sido el más destacado, consiguiendo que en el post-test el $60 \%$ de los alumnos las utilizaran como parte indispensable del proceso, tanto como herramienta auto-evaluativa durante las operaciones algebraicas, comprobando que las unidades resultantes concuerdan con las correspondientes a la medida de la magnitud implicada, como mecanismo casual para encontrar las relaciones entre las magnitudes (ver figura 9). Y no solo eso, sino que el $72 \%$ de los estudiantes las han utilizado correctamente a lo largo de todo el proceso durante el posttest (ver figura 10).

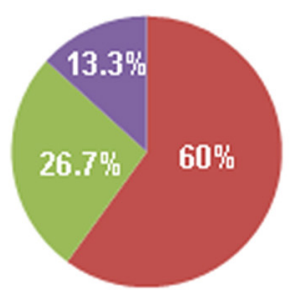

PRE-TEST

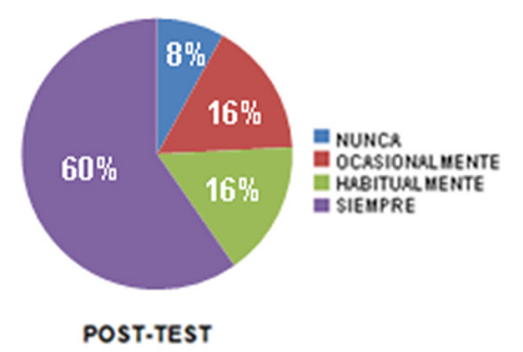

Figura 9: Diagrama de sectores comparativos del uso de unidades de medida pre y post

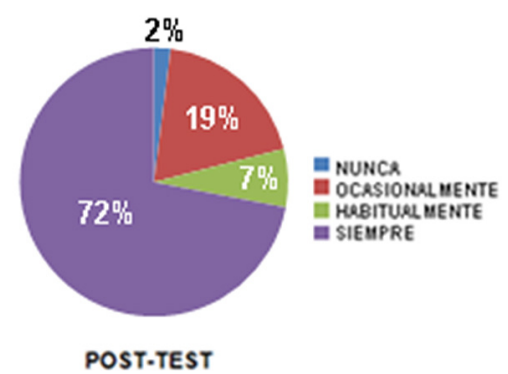

Figura 10: Diagrama de sectores para la validez del uso de unidades de medida post

Sin embargo, lo más destacable es la existencia de la dependencia encontrada en el posttest entre las variables 1 y 4 y las variables 1 y 5 : "estrategia-uso de unidades de medida" y "estrategia-validez de las unidades de medida". Esta dependencia se determinó mediante el índice estadístico chi-cuadrado, obteniendo en ambos casos valores por debajo del 0.05.

Las tablas 3 y 4 ofrecen las comparaciones estadísticas entre las variables 1 y 4 y las variables 1 y 5 respectivamente. 
Tabla 3: Estrategia utilizada - Uso de unidades

\begin{tabular}{|c|c|c|c|c|c|c|c|c|c|c|}
\hline & \multicolumn{9}{|c|}{ Uso de unidades } \\
\hline & & \multicolumn{2}{|c|}{ Nunca } & \multicolumn{2}{|c|}{ Ocasionalmente } & \multicolumn{2}{|c|}{ Habitualmente } & \multicolumn{2}{|c|}{ Siempre } & Total \\
\hline \multirow{4}{*}{$\begin{array}{l}\text { Estrategia } \\
\text { utilizada }\end{array}$} & regla de 3 & 0 & $0 \%$ & 0 & $0 \%$ & 2 & $67 \%$ & 1 & $33 \%$ & 3 \\
\hline & fórmulas & 1 & $14 \%$ & 5 & $71 \%$ & 1 & $14 \%$ & 0 & $0 \%$ & 7 \\
\hline & $\begin{array}{l}\text { otra } \\
\text { estrategia }\end{array}$ & 4 & $40 \%$ & 1 & $10 \%$ & 2 & $20 \%$ & 3 & $30 \%$ & 10 \\
\hline & $\begin{array}{l}\text { Factor } \\
\text { conversión }\end{array}$ & 0 & $0 \%$ & 4 & $10 \%$ & 5 & $12 \%$ & 33 & $79 \%$ & 42 \\
\hline \multicolumn{2}{|c|}{ Total } & 5 & $8 \%$ & 10 & $16 \%$ & 10 & $16 \%$ & 37 & $60 \%$ & 62 \\
\hline
\end{tabular}

Tabla 4: Estrategia utilizada - Validez de las unidades

\begin{tabular}{|c|c|c|c|c|c|c|c|c|c|c|}
\hline & \multicolumn{9}{|c|}{ Validez de las unidades } \\
\hline & & \multicolumn{2}{|c|}{ Nunca } & \multicolumn{2}{|c|}{ Ocasionalmente } & \multicolumn{2}{|c|}{ Habitualmente } & \multicolumn{2}{|c|}{ Siempre } & \multirow{2}{*}{$\frac{\text { Total }}{3}$} \\
\hline \multirow{4}{*}{$\begin{array}{l}\text { Estrategia } \\
\text { utilizada }\end{array}$} & regla de 3 & 0 & $0 \%$ & 2 & $67 \%$ & 0 & $0 \%$ & 1 & $33 \%$ & \\
\hline & fórmulas & 0 & $0 \%$ & 3 & $50 \%$ & 1 & $17 \%$ & 2 & $33 \%$ & 6 \\
\hline & $\begin{array}{l}\text { otra } \\
\text { estrategia }\end{array}$ & 1 & $14 \%$ & 1 & $14 \%$ & 0 & $0 \%$ & 5 & $71 \%$ & 7 \\
\hline & $\begin{array}{l}\text { Factor } \\
\text { conversión }\end{array}$ & 0 & $0 \%$ & 5 & $12 \%$ & 3 & $7 \%$ & 34 & $81 \%$ & 42 \\
\hline \multicolumn{2}{|c|}{ Total } & 1 & $8 \%$ & 11 & $19 \%$ & 4 & $7 \%$ & 42 & $72 \%$ & 58 \\
\hline
\end{tabular}

De estos resultados resaltamos como el $79 \%$ de los alumnos que utilizan los factores de conversión utilizan siempre las unidades como herramienta en la resolución y argumentación. Además, el $81 \%$ de ellos las han utilizado correctamente a lo largo del todo el proceso. Un ejemplo de esto lo podemos ver en la figura 11.

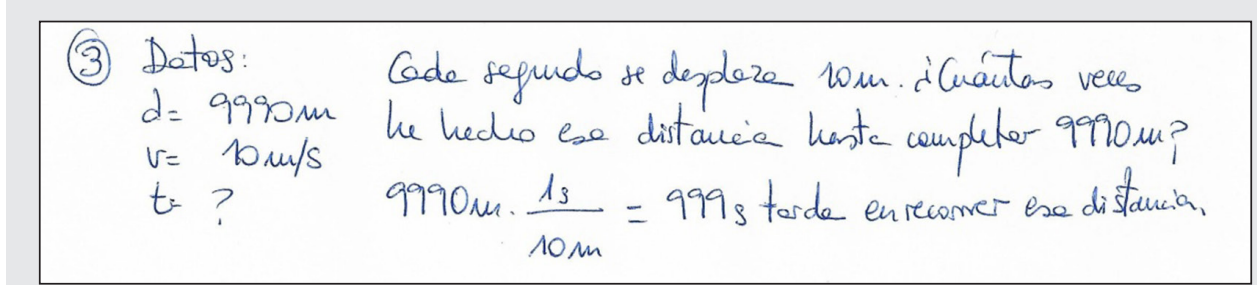

Ejemplo de validez de unidades utilizando factor de conversión para un MRU

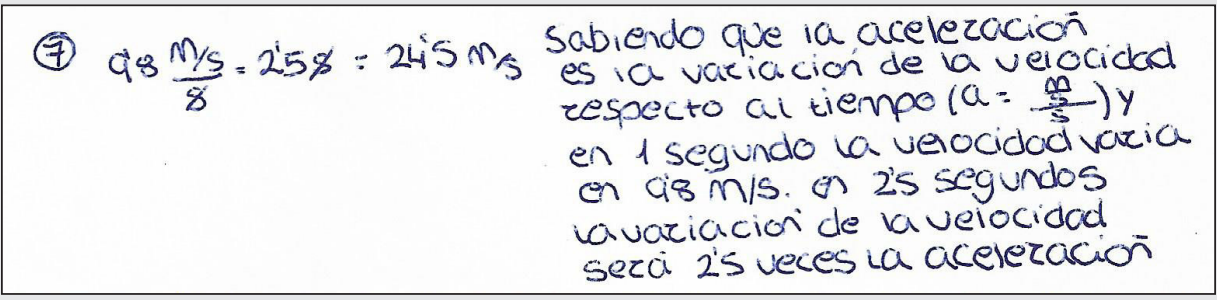

Ejemplo de validez de unidades utilizando factor de conversión para un MRUA

Figura 11: Ejemplos de validez en el uso de unidades de medida utilizando factor de conversión como estrategia 
Esto contrasta claramente con los alumnos que han seguido utilizando una estrategia tradicional mediante fórmulas, donde el $71 \%$ de ellos han utilizado las unidades de medida solo ocasionalmente y únicamente al final de la operación. Si además atendemos a la validez del uso de las mismas, solo el $33 \%$ de ellos lo han hecho adecuadamente (ver figura 12).

$$
\text { 7) } \begin{array}{rlrl}
V_{0} & =0 & a=\frac{V_{F}-V_{O}}{t_{T}-t_{0}} & V_{E}=25 \cdot 10=25 \mathrm{~m} \\
t_{0}=0 & 10=\frac{V_{F}-0}{25-0} & \text { Recone una velecidad } \\
t_{T}=2^{2} 50 & \text { de } 25 \mathrm{~m} & \\
a & =10 & &
\end{array}
$$

Figura 12: Ejemplo de uso no válido de las unidades de medida usando fórmulas algebraicas

Como punto intermedio quedan los alumnos que han utilizado regla de tres $u$ otros registros de representación, destacando que el $67 \%$ de los primeros sólo han hecho el uso correcto de las unidades de medida en alguna ocasión, mientras que los que han utilizado la segunda estrategia, el $81 \%$ lo ha hecho siempre correctamente (Ver figura 13)

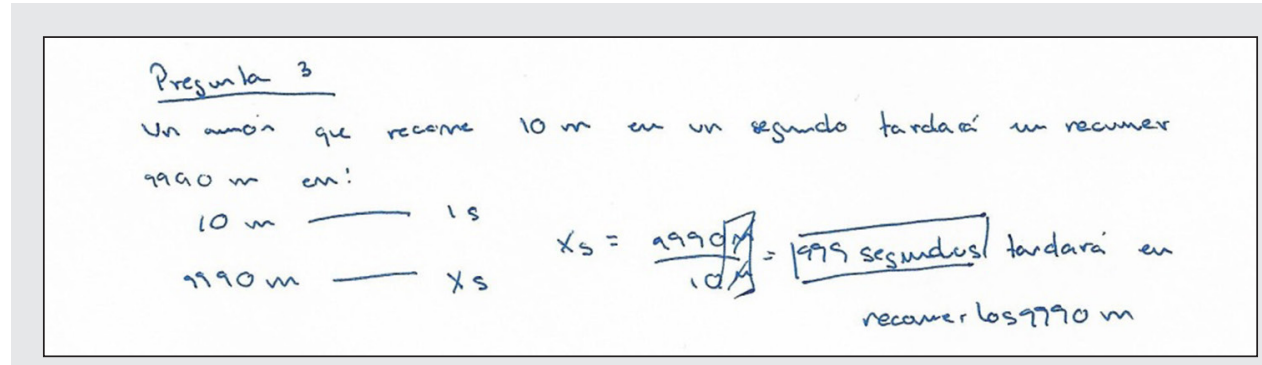

Ejemplo de no validez de unidades utilizando reglas de tres

$$
\begin{aligned}
& \text { (t) } \\
& x_{0}=0 \mathrm{~m} / \mathrm{s} \quad t_{1}=0 \quad t_{2}=2,5 \mathrm{~s} \quad a=90 \mathrm{wis}^{2} \\
& 7_{1}^{10 \text { uns }} 20 \mathrm{mins} 25 \mathrm{mis}, v=25 \mathrm{wis}
\end{aligned}
$$

Por cada segundo, avuruta louls br velocidod si pasan 2 iss habrá anmentado 25 un según le grapaca de. arsiba.

Ejemplo de validez de unidades utilizando registros de representación pictográficos

Figura 13: Ejemplos de validez de unidades de medida según la estrategia utilizada

\section{Contenidos actitudinales}

El análisis de los datos recogidos en el test de actitudes, antes y después de implementar el proceso de enseñanza-aprendizaje muestra una diferencia significativa a nivel estadístico con un incremento positivo en la intensidad de las actitudes favorables en todas sus componentes y dimensiones (ver tablas 5 y 6). Si comparamos las medias totales, observamos un aumento de 0,72 puntos desde el pre al post, destacando el cambio que corresponde a la dimensión conductual con una diferencia de 0.82 puntos. 
Tabla 5: Puntuación media de las actitudes antes de la variable independiente

\begin{tabular}{|c|l|c|c|c|c|}
\hline \multirow{2}{*}{$\begin{array}{c}\text { ACTITUDES } \\
\text { PREVIAS }\end{array}$} & \multicolumn{4}{|c|}{ DIMENSIÓN } \\
\cline { 3 - 6 } & Hacia la Ciencia & $\begin{array}{c}\text { Hacia la Física } \\
\text { como asignatura }\end{array}$ & $\begin{array}{c}\text { Hacia la Didáctica } \\
\text { de la Ciencia }\end{array}$ & Media \\
\hline \multirow{3}{*}{$\begin{array}{c}\text { COMPO- } \\
\text { NENTE }\end{array}$} & Cognitiva & 3.65 & 3.42 & 3.53 & 3.53 \\
\cline { 2 - 6 } & Afectiva & 2.99 & 2.77 & 2.87 & 2.88 \\
\cline { 2 - 6 } & Conductual & 2.36 & 2.79 & 3.61 & 2.92 \\
\cline { 2 - 6 } & Media & 3.00 & 2.99 & 3.67 & 3.11 \\
\hline
\end{tabular}

Tabla 6: Puntuación media de las actitudes después de la variable dependiente

\begin{tabular}{|c|l|c|c|c|c|}
\hline \multirow{2}{*}{$\begin{array}{c}\text { ACTITUDES } \\
\text { POSTERIORES }\end{array}$} & \multicolumn{4}{|c|}{ DIMENSIÓN } \\
\cline { 2 - 6 } \multicolumn{2}{|c|}{} & Hacia la Ciencia & $\begin{array}{c}\text { Hacia la Física } \\
\text { como asignatura }\end{array}$ & $\begin{array}{c}\text { Hacia la Didáctica } \\
\text { de la Ciencia }\end{array}$ & Media \\
\hline \multirow{3}{*}{$\begin{array}{c}\text { COMPO- } \\
\text { NENTE }\end{array}$} & Cognitiva & 3,94 & 4,10 & 4,11 & 4,05 \\
\cline { 2 - 6 } & Afectiva & 3,79 & 3,62 & 3,59 & 3,66 \\
\cline { 2 - 6 } & Conductual & 3,32 & 3,83 & 4,22 & 3,79 \\
\cline { 2 - 6 } & Media & 3,68 & 3,85 & 3,97 & 3,83 \\
\hline
\end{tabular}

A continuación, analizaremos los resultados para las variables 6, 7 y 8 no solo a partir de los diagramas de dispersión representadas desde la figura 14 hasta la 22, sino que además se han interpretado las respuestas a los enunciados del test de actitudes.

\section{Variable 6: Componente cognitiva}

La dispersión entre las distintas respuestas de los alumnos antes y después de la instrucción para la "componente cognitiva" nos hace darnos cuenta que el cambio más significativo ha recaído en las dimensiones de la Física y de la Didáctica de la Ciencia (ver figuras 14,15 y 16).

En la figura 15 se puede apreciar que había una parte importante de alumnos que creían que el estudio de la Física se basa en una memorización y mecanización de conceptos y fórmulas para aplicarlas a la resolución de problemas numéricos. Esto es congruente con los datos recogidos en el pre-test, donde la gran mayoría de los alumnos que respondieron utilizaron fórmulas como estrategia de resolución. Parece claro que, si tenían esta imagen de la Física, sus creencias acerca de la Didáctica de las Ciencias, antes de nuestra intervención educativa, fuera la de impartir conocimientos previamente establecidos, limitando la acción del alumno a recibir información como un proceso de “copia” (Figura 16).

Sin embargo, vemos que, finalizado el estudio, se ha producido un giro en la visión que tiene sobre la Física y su didáctica. Dadas las respuestas del alumnado se puede apreciar que han interiorizado que hay otras formas de aprender conocimientos científicos y, por ende, de trasmitirlos en su futuro profesional buscando que sus alumnos construyan los conceptos desde su propia perspectiva. 

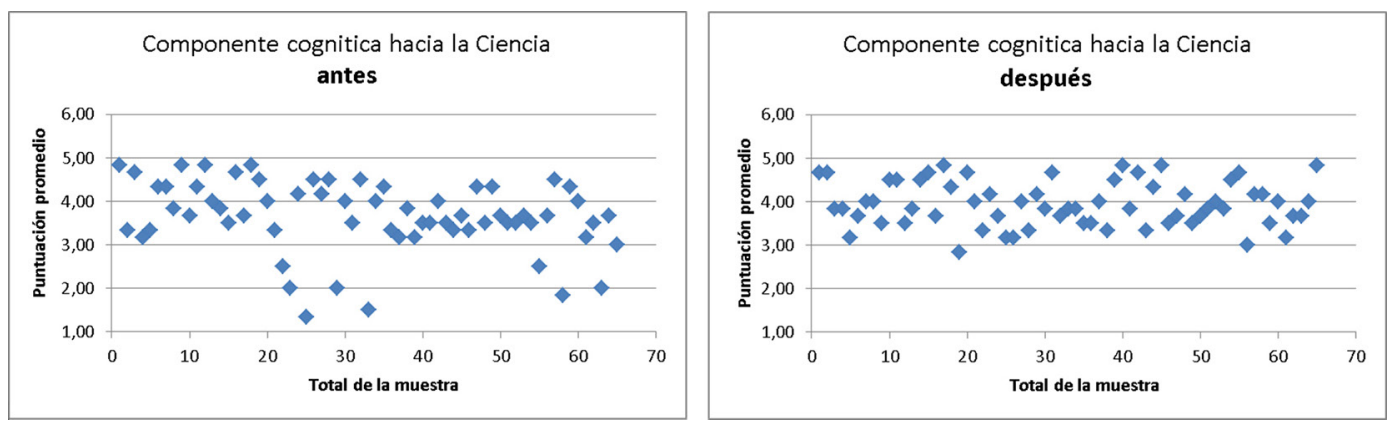

Figura 14: Comparativa de dispersiones para la componente cognitiva hacia la Ciencia antes y después.
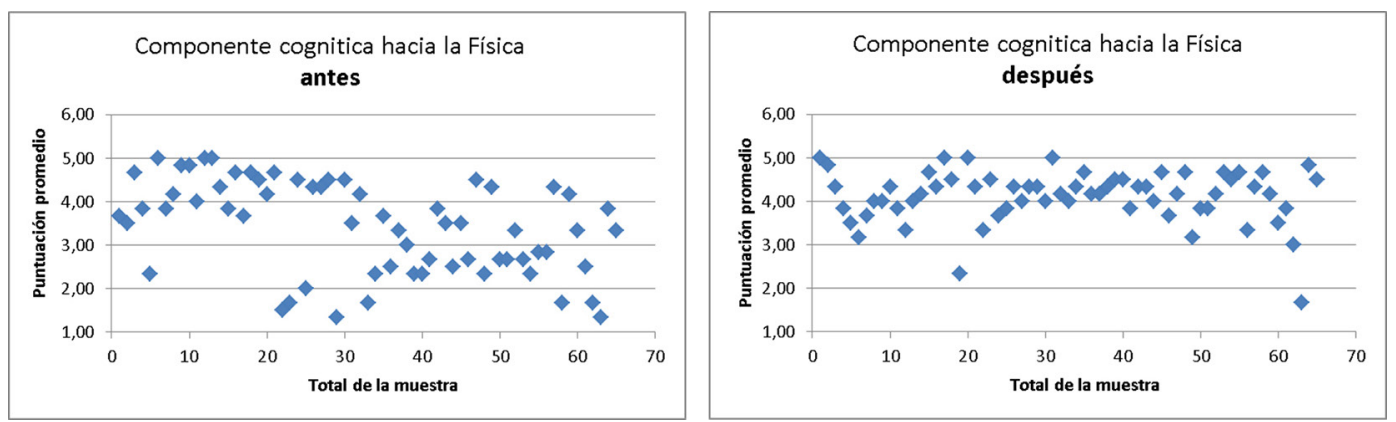

Figura 15: Comparativa de dispersiones para la componente cognitiva hacia la Física como asignatura antes y después.
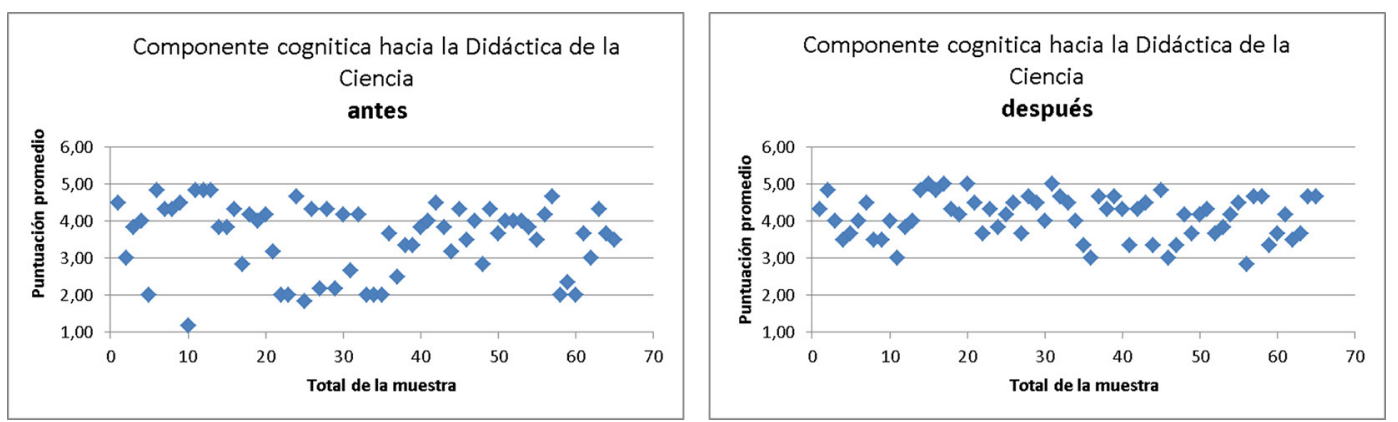

Figura 16: Comparativa de dispersiones para la componente cognitiva hacia la Didáctica de la Ciencia antes y después.

\section{Variable 7: Componente afectiva}

Las figuras 17,18 y 19, junto con la tabla 5, muestran como la componente afectiva, antes de la intervención registra la media más baja en intensidad de las tres componentes, destacando la dimensión hacia la Física como asignatura. Más del $50 \%$ de los alumnos sentían total apatía por la Ciencia, siendo el estudio de la Física poco motivador y les producía cierta ansiedad pensar que tienen que razonar para poder comprender los conceptos Físicos, puesto que no se veían capacitados para ello. Además, les preocupaba no tener herramientas suficientes para enseñar Ciencia.

En esta ocasión, también se ha podido comprobar que en el después, tal y como se aprecia en dichas figuras, existe un cambio favorable en la intensidad de las actitudes afectivas en las tres componentes. Un aprendizaje contextualizado ha provocado que una 
parte del alumnado quiera saber más sobre Ciencia y sus avances científicos, han cambiado la ansiedad por la tranquilidad de saber que son capaces de comprender y construir los conceptos Físicos y esto les ha ayudado a sentir alivio como futuros profesores de ciencias.
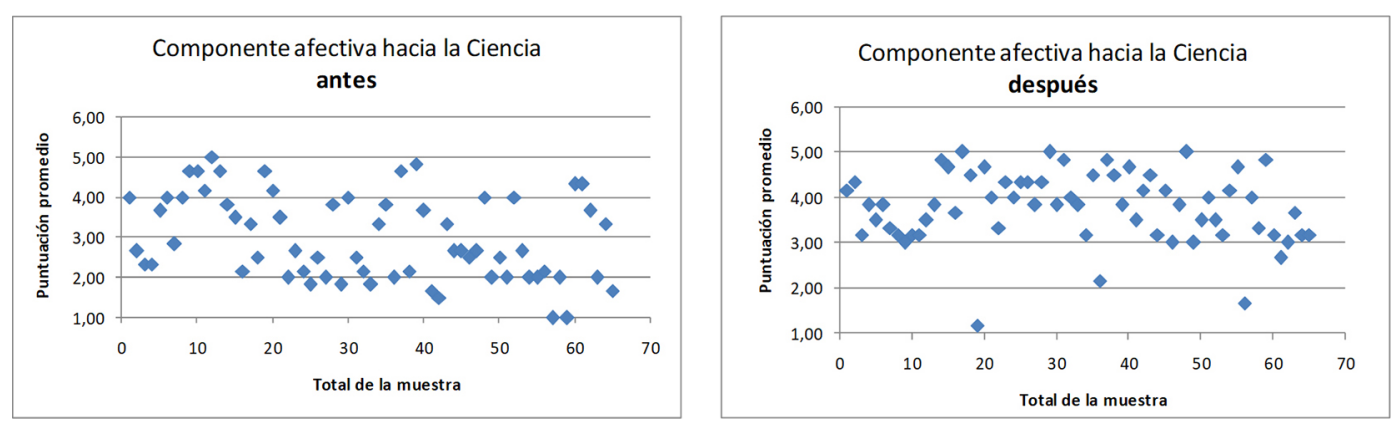

Figura 17: Comparativa de dispersiones para la componente afectiva hacia la Ciencia antes y después.
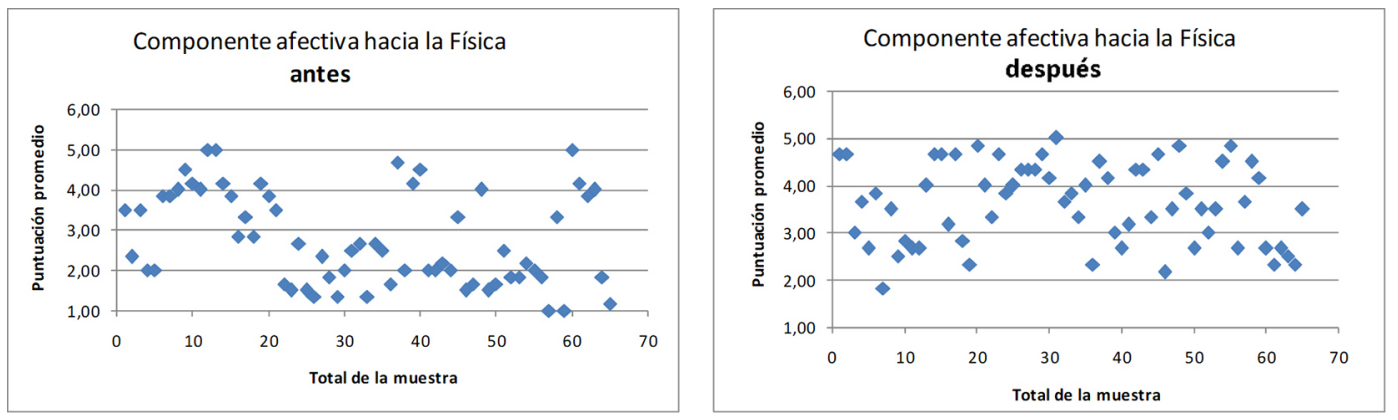

Figura 18: Comparativa de dispersiones para la componente afectiva hacia la Física como asignatura antes y después.
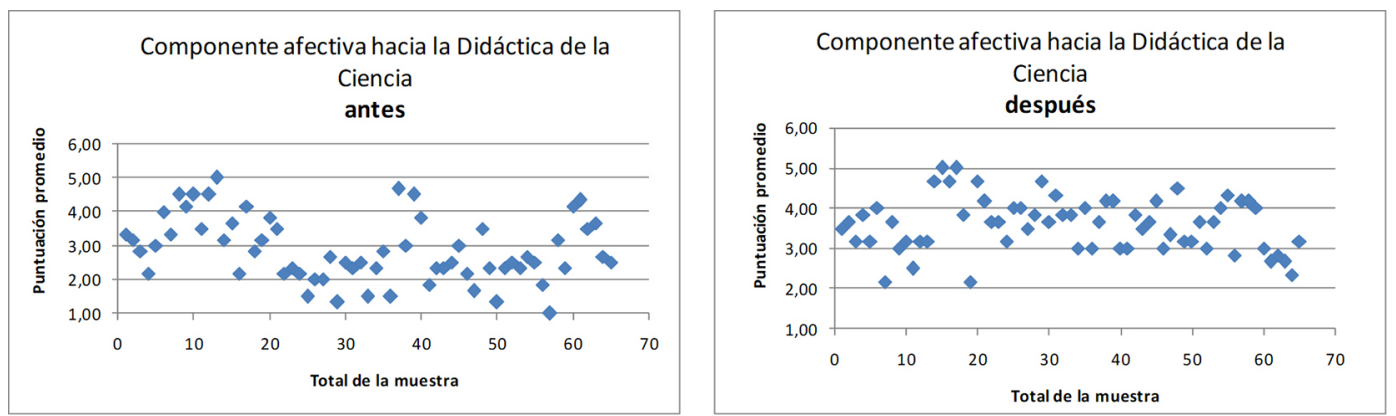

Figura 19: Comparativa de dispersiones para la componente afectiva hacia la Didáctica de la Ciencia antes y después.

Variable 8: Componente conductual

Una vez más se observó un cambio en las actitudes de los alumnos hacia conductas más positivas hacia las tres dimensiones (ver figuras 20, 21 y 22). Mientras más de la mitad de los alumnos mostraban muy poca motivación para acercarse al conocimiento científico, asumiendo un rol pasivo en las clases de Física antes, se pone de manifiesto en el después, por un lado, que los estudiantes están dispuestos a conocer la ciencia y sus avances científicos a través de documentales o revistas, disfrutando de ellos al poder comprenderlos 
mejor y pudiendo participar, así, en debates que puedan surgir en su día a día; por otro, ahora comprenden la importancia y el interés que suscita participar más activamente en los debates surgidos en clase de Física, razonando y argumentado sus opiniones.

Mención aparte merece la componente conductual hacia la Didáctica de la Ciencia ya que partimos de la base de que los alumnos ya tenían actitudes bastante favorables antes de la realización del estudio (figura 22). Creemos que esto es debido a que, al estar formándose como futuros maestros, deben tener una buena predisposición hacia la enseñanza en general. Sin embargo, esto se ha acrecentado de manera sustancial una vez que los alumnos han participado en las clases de una forma mucho más activa. De sus respuestas en el test de actitudes se induce que, en su futuro profesional, están dispuestos a involucrar a sus alumnos en un aprendizaje por indagación a partir de sus experiencias previas, quitándole el protagonismo al libro de texto como tal.
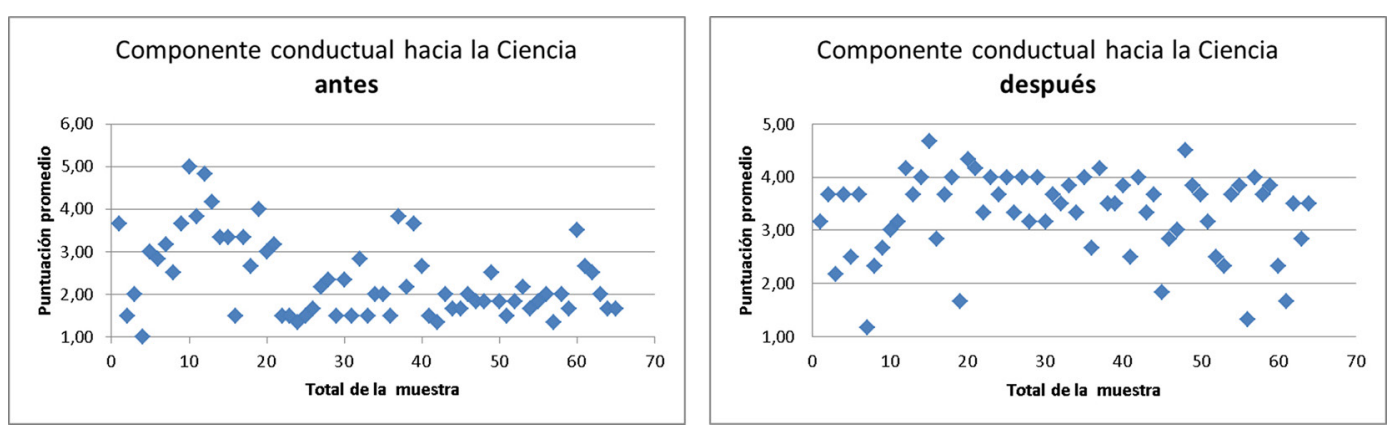

Figura 20: Comparativa de dispersiones para la componente conductual hacia la Ciencia antes y después.
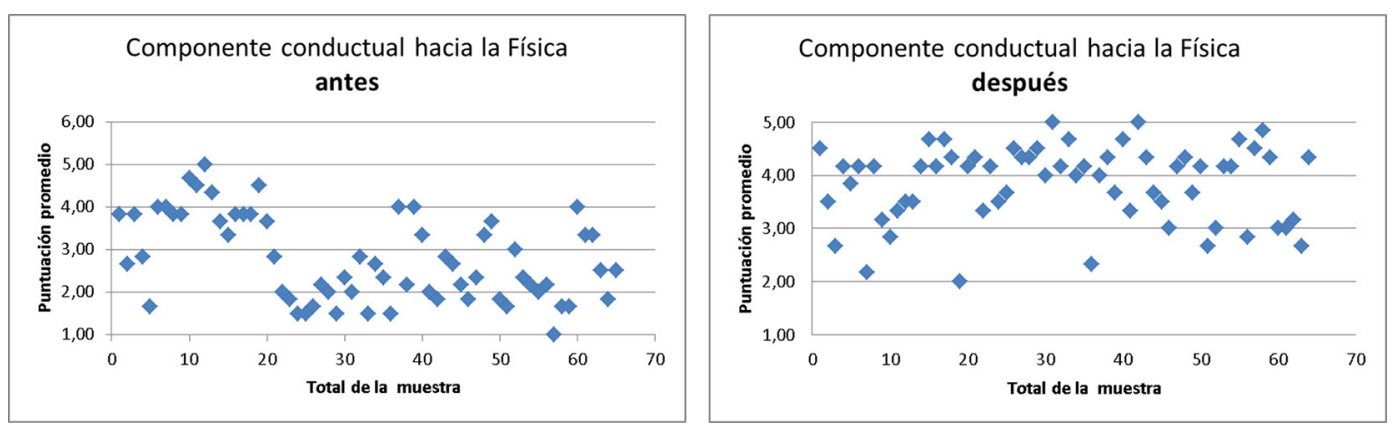

Figura 21: Comparativa de dispersiones para la componente conductual hacia la Física como asignatura antes y después.
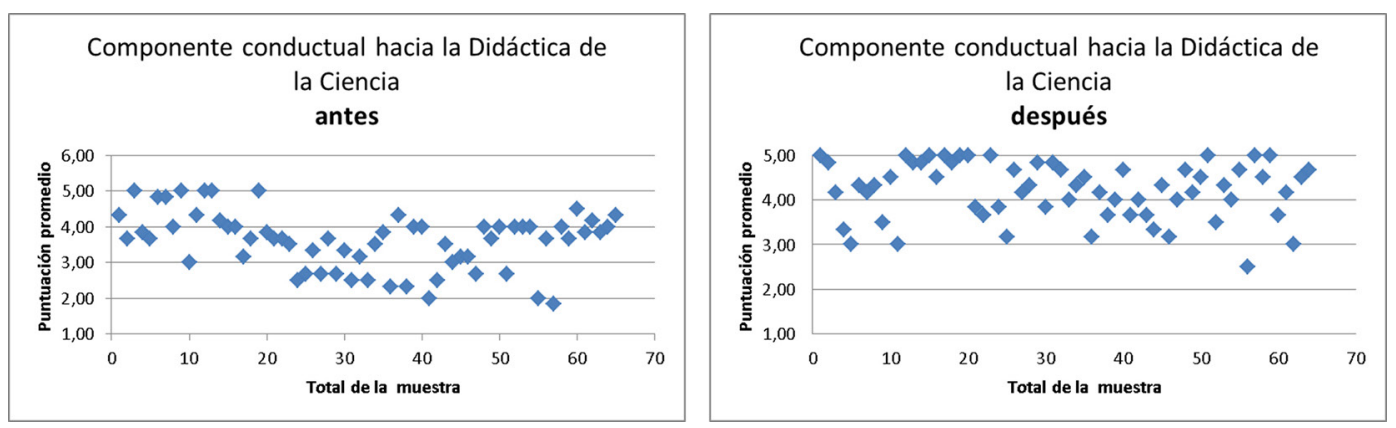

Figura 22: Comparativa de dispersiones para la componente conductual hacia la Didáctica de la Ciencia antes y después. 


\section{Conclusiones e Implicaciones didácticas}

El análisis de los datos recogidos antes y después de la aplicación de la estrategia de enseñanza y aprendizaje, muestra el desarrollo del alumno tanto a nivel de procedimental como actitudinal.

\section{Contenidos procedimentales}

El avance procedimental se vio corroborado en las cinco variables estudiadas.

Variable 1: estrategia seleccionada

Se considera así debido al aumento de estrategias escogidas para la resolución de problemas distintas a las tradicionales, donde la aplicación de fórmulas estandarizaras, sin una argumentación que las sustente, entorpece la necesidad de la comprensión del problema y, por tanto, se encamina más hacia dar un dato final que a la construcción y relación de los conceptos que intervienen en el fenómeno estudiado.

\section{Variables 2 y 3: uso y validez de la argumentación}

Presentando cambios en sus niveles de reflexión, y explicitando el nexo de unión entre los datos iniciales y la conclusión obtenida. Aunque también es cierto que una parte no despreciable de ellos sigue sin comprender en qué consiste un buen argumento en Ciencias, confundiéndola con meras explicaciones del proceso llevado, apoyando así los resultados de Bravo et al. (2009)

Variables 4 y 5: uso y validez de las unidades de medida

Utilizándolas como herramienta necesaria para encontrar las relaciones entre las magnitudes implicadas y como mecanismo para la autoevaluación de su proceso de resolución.

\section{Contenidos actitudinales}

El significativo aumento en la intensidad de actitudes positivas también se hizo patente en sus tres componentes para cada una de las dimensiones estudiadas:

\section{Variable 6: Componente cognitiva}

Los resultados obtenidos en esta componente hace plantearnos, al igual que hicieron García-Ruiz y Orozco (2008), la necesidad de introducir una formación inicial para maestros que favorezca una reflexión epistemológica sobre la Ciencia y sus relaciones con la sociedad, de modo que no solo se estudie Ciencia sino también el significado de la Ciencia en el mundo actual dándoles a conocer diversas formas de entenderla y dejando a un lado la imagen de una Ciencia y su didáctica autoritaria, estática y difícil.

\section{Variable 7: Componente afectiva}

Una vez más ha queda reflejado ese rechazo hacia la Ciencia en general (Robles et al., 2015), hacia la asignatura de Física (Brígido et al. 2009) y hacia la Didáctica de las Ciencias (García-Ruiz y Orozco, 2008). Sin embargo, con un pequeño acercamiento hacia una Ciencia más plural, crítica y significativa se ha promovido un cambio en las actitudes de los alumnos hacia la misma, sintiéndose capaces de comprender y construir conceptos científicos desde su propia perspectiva. Esto nos lleva a estar de acuerdo con Retama-Alvarado, de las Heras-Pérez, Vázquez-Bernal y Jiménez-Pérez (2018) en la necesidad de incorporar en la formación del docente una educación emocional que incluya estrategias de metacognición y autorregulación emocional como competencias dentro de su CDC. 


\section{Variable 8: Componente conductual}

Tal y como ya expresamos, hemos comprobado que la mejora de esta componente está condicionada por el resultado de las otras dos, puesto que para que un estudiante quiera acercarse a la Ciencia y hacia la didáctica de la misma se necesita que se produzca un aprendizaje emocionalmente significativo (Mora, 2016), donde la Ciencia deje de ser algo ajeno a ellos e incorporarla como parte de sus vidas. Esto les ayudará a integrar en su CDC estrategias de enseñanza más acordes a lo que el aprendizaje de la Ciencia demanda.

Por lo que podemos concluir que un proceso de aprendizaje que incorpore la argumentación como eje metodológico, de modo que permita a los alumnos una interrelación de conceptos, la búsqueda de soluciones de forma autónoma y la elaboración de sus propias conclusiones, dando sentido y significación a los fenómenos aprendidos, supone un cambio de actitud hacia la Ciencia en general y hacia la asignatura de Física en particular, apreciándola y valorándola por su contenido. Todo esto puede facilitar un cambio en las creencias, actitudes y expectativas que tienen como futuros docentes en el área de Ciencias Experimentales.

\section{Reconocimiento}

Agradecemos a la Asociación de Profesores e Investigadores en CC.EE. (APICE) el 20 premio recibido, en la convocatoria de 2018 , al TFM del que procede este trabajo

\section{Referencias bibliográficas}

Archila, P. A. (2012). La investigación en argumentación y sus implicaciones en la formación inicial de profesores de ciencias. Revista Eureka sobre Enseñanza y Divulgación de las Ciencias, 9(3), 361-375. Recuperado de: http://hdl.handle.net/10498/14864

Brígido M., Caballero, A., Bermejo, M. L., y Mellado, V. (2009). Las emociones sobre la enseñanza y aprendizaje de las ciencias en estudiantes de Maestro de Primaria. Revista Electrónica de Motivación y Emoción, XI(31).

Brígido, M. y Borrachero, A. B. (2011). Relación entre autoconcepto, autoeficacia y autorregulación en ciencias de futuros maestros de Primaria. INFAD Revista de Psicología, 1(2)2(1), 107-113.

Bravo, B., Puig, B. y Jiménez-Aleixandre, M. P. (2009). Competencias en el uso de pruebas en argumentación. Educación Química, 20(2), 137-142. DOI: http://dx.doi. org/10.1016/S0187-893X(18)30020-X

Buforn, A. y Fernández, C. (2014). Conocimiento de matemáticas especializado de los estudiantes para maestro de primaria en relación al razonamiento proporcional. Boletim de Educaçao Matemática (BOLEMA), 28(48), 21-41. DOI: https://dx.doi. org/10.1590/1980-4415v28n48a02

Custodio, E., Márquez, C. y Sanmartí, N. (2015). Aprender a justificar científicamente a partir del estudio del origen de los seres vivos. Enseñanza de las Ciencias, 33(2), 133-155. DOI: https://doi.org/10.5565/rev/ensciencias.1316

Fuentes Vargas, C. (2016) Preconceptos de cinemática y fuerza en estudiantes que inician sus estudios de ingeniería. Revista Electrónica de Enseñanza de las Ciencias 15(1), 43-52.

García García, J. J. (2000). La solución de situaciones problemáticas: una estrategia didáctica para la enseñanza de la química. Enseñanza de las Ciencias, 18(1), 113-129. Recuperado de: http://hdl.handle.net/10495/3596 
García-Ruiz, M. y Sánchez Hernández, B. (2006). Las actitudes relacionadas con las ciencias naturales y sus repercusiones en la práctica docente de profesores de primaria. Perfiles educativos vol. XXVIII, 114, 61-89.

García-Ruiz, M. y Orozco, L. (2008). Orientando un cambio de actitud hacia las ciencias naturales y su enseñanza en profesores de educación primaria. Revista Electrónica de Enseñanza de las Ciencias, 7(3), 539-568.

Goleman, D. (1996). La inteligencia emocional. Barcelona: Kairós.

Guirado, A. M., Mazzitelli, C. y Maturano, C. (2013). La resolución de problemas en la formación del profesorado en Ciencias: análisis de las opiniones y estrategias de los estudiantes. Revista Eureka sobre Enseñanza y Divulgación de las Ciencias, 10 (Núm. Extraordinario), 821-835. Recuperado de: http://hdl.handle.net/10498/15630

Márquez Bargalló, C. (2011). ¿Cómo promover el desarrollo de la competencia científica? En M. P. Jiménez-Aleixandre, y L., Fernández López, (Ed.). Cuaderno de indagación en el aula y competencia científica. Madrid: Ministerio de Educación.

Martínez-Artero, R., y Pro, A. (2003). Actitudes hacia las ciencias de los alumnos de educación primaria de la región de Murcia. En las II Jornadas de los Máster en Investigación e Innovación de Educación Infantil y Educación Primaria.

Maturana, H. (2001). Emociones y lenguaje en Educación y Política. Santiago de Chile: Domen.

McDermott, L. C. (1998). Concepciones de los alumnos y resolución de problemas en mecánica. En A. Tiberghien, E. Leonard Jossem, y J. Barojas (Eds.). Resultados de Investigaciones en Didáctica de la Física en la Formación de Docentes. Internacional Commission on Physics Education.

Mellado, V., Garritz, A., y Brígido, M. (2009). La dimensión afectiva olvidada del conocimiento didáctico del contenido de los profesores de ciencias. Enseñanza de las Ciencias, (Num. Extra), 347-351.

Mora, F. (2016) Neuroeducación. Solo se puede aprender aquello que se ama. Madrid: Alianza Editorial.

OCDE (2002). La definición y selección de competencias clave (DeSeCo). Resumen ejecutivo.

Ponce, V.M. (1997). La comprensión de los fenómenos físicos en alumnos del bachillerato. Revista Electrónica Sinéctica, 11, 1-11.

Retana-Alvarado, D. A., De las Heras-Pérez, M. Á., Vázquez-Bernal B. y Jiménez-Pérez R. (2018). El cambio en las emociones de maestros en formación inicial hacia el clima de aula en una intervención basada en investigación escolar. Revista Eureka sobre Enseñanza y Divulgación de las Ciencias, 15(2), 2602. DOI https://doi.org/10.25267/ Rev_Eureka_ensen_divulg_cienc.2018.v15.i2.2602

Ríordáin, M., Johnston, J., y Walshe, G. (2015): Making mathematics and science integration happen: key aspects of practice. International Journal of Mathematical Education in Science and Technology, 47(2), 233-255. DOI: https://doi.org/10.1080 /0020739X.2015.1078001

Robles, A., Solbes, J., Cantó, J. R. y Lozano, Ó. R. (2015). Actitudes de los estudiantes hacia la ciencia escolar en el primer ciclo de la Enseñanza Secundaria Obligatoria. Revista Electrónica de Enseñanza de las Ciencias, 14(3), 361-376. 
Shulman L. S. (1986) Those who understand: knowledge growth in teaching. Educational Research 57(1), 1-22. DOI: https://doi.org/10.3102/0013189X015002004

Solbes, J. (2011). ¿'Por qué disminuye el alumnado de ciencias? Alambique, Didáctica de las Ciencias Experimentales, (67), 53-61.

Toulmin, S. (1958). The uses ofargument. Cambridge: Cambridge: University Press. Traducción española de Morrás, M. y Pineda, V. (2007). Los usos de la argumentación. Barcelona: Península.

Vázquez A. y Manassero M.A. (2016) Los contenidos de ciencia, tecnología y sociedad en los nuevos currículos básicos de la educación secundaria en España. Indagatio Didactica, 8(1), 1017-1032. 


\section{ANEXO 1. Pretest}

A continuación, se incluye una parte del pretest empleado para un Movimiento Rectilíneo y Uniforme a modo de ejemplo ilustrativo.

\section{Situación problema 1}

\section{¿Cómo funciona un radar por tramo?}

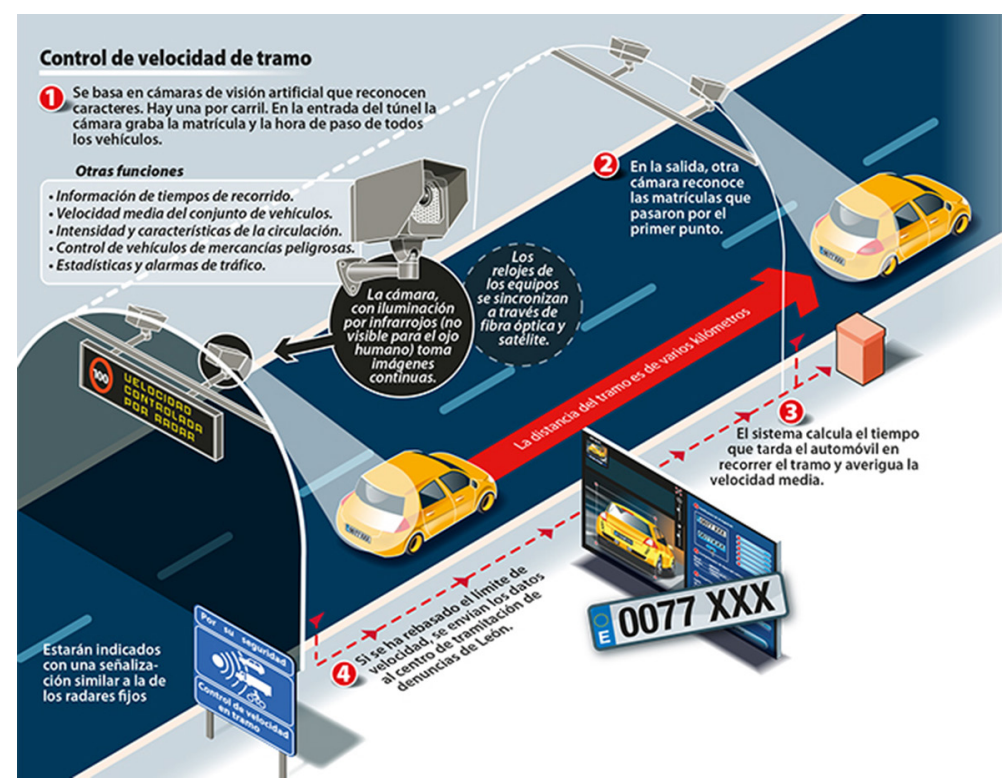

Esta infografía explica el funcionamiento de los radares de tramo, basados en las cámaras de visión artificial (Tráfico y Seguridad Vial/Dlirios)

La DGT ha colocado un radar por tramo en un punto estratégico de Despeñaperros donde se han estado registrando bastantes accidentes en los últimos años.

\begin{tabular}{|c|c|c|c|c|c|c|}
\hline Ubicación & Carretera & $\begin{array}{c}\text { Distancia } \\
\text { de tramo }\end{array}$ & $\begin{array}{c}\text { P.K. final } \\
\text { de tramo }\end{array}$ & Provincia & Sentido & $\begin{array}{c}\text { Velocidad } \\
\text { permitida }\end{array}$ \\
\hline Despeñaperros & A-4 & $3130 \mathrm{~m}$ & 245.229 & Jaén & Decreciente & $100 \mathrm{Km} / \mathrm{h}$ \\
\hline
\end{tabular}

María va camino a Madrid junto con su amigo Pedro cuando su coche pasa justo por delante de una de las cámaras de un radar de tramo. Un minuto y medio después pasan por la otra cámara de final del tramo.

PREGUNTA 1: Si decimos que el coche ha viajado durante ese tramo con un movimiento rectilíneo y uniforme, ¿Qué restricciones debe cumplir su movimiento para que se cumpla dicha afirmación?

PREGUNTA 2: ¿Le llegará a María una multa a casa? Justifica la respuesta

Datos: Distancia recorrida $=3.130 \mathrm{Km}$

Tiempo empleado para recorrer esa distancia $=1.5 \mathrm{~min}$

Velocidad máxima de tramo $=100 \mathrm{Km} / \mathrm{h}$ 
ANEXO 2: Test de actitudes

COMPONENTE COGNITIVA

\begin{tabular}{|c|c|l|}
\hline VALORACIONES & CLAVE & \multicolumn{1}{|c|}{ Descripción de la valoración } \\
\hline Totalmente de acuerdo & TA & $\begin{array}{l}\text { Si compartes el contenido del enunciado tal y como está } \\
\text { redactado }\end{array}$ \\
\hline Parcialmente de acuerdo & PA & $\begin{array}{l}\text { Si compartes el contenido central del enunciado en } \\
\text { alguno aspectos }\end{array}$ \\
\hline No estoy seguro & N & Si estás indeciso con el enunciado \\
\hline Parcialmente en desacuerdo & PD & $\begin{array}{l}\text { Si no compartes el contenido central del enunciado, } \\
\text { aunque si estás de acuerdo con alguno de los aspectos }\end{array}$ \\
\hline Totalmente en desacuerdo & TD & $\begin{array}{l}\text { Si no compartes el contenido central del enunciado en } \\
\text { ninguno de sus aspectos. }\end{array}$ \\
\hline
\end{tabular}

\begin{tabular}{|c|c|c|c|c|c|c|}
\hline & ENUNCIADOS & $\begin{array}{l}\text { Totalmente } \\
\text { desacuerdo }\end{array}$ & $\begin{array}{c}\text { Parcialmente } \\
\text { desacuerdo }\end{array}$ & $\begin{array}{l}\text { No estoy } \\
\text { seguro }\end{array}$ & $\begin{array}{c}\text { Parcialmente } \\
\text { acuerdo }\end{array}$ & $\begin{array}{l}\text { Totalmente } \\
\text { acuerdo }\end{array}$ \\
\hline 1 & $\begin{array}{l}\text { Es necesario que los científicos siempre estén al día de } \\
\text { lo que acontece ya que la ciencia no es algo estable e } \\
\text { incuestionable, sino algo que siempre está en tela de } \\
\text { juicio. }\end{array}$ & & & & & \\
\hline 2 & $\begin{array}{l}\text { Un buen entendimiento de los conceptos de la asigna- } \\
\text { tura de Física me ayudaría comprender mejor el mun- } \\
\text { do que me rodea. }\end{array}$ & & & & & \\
\hline 3 & $\begin{array}{l}\text { En las clases de ciencia en primaria, el alumno debe } \\
\text { limitarse a recibir información, hacer un proceso de } \\
\text { "copia" de la realidad y reproducirla tal cual. }\end{array}$ & & & & & \\
\hline 4 & $\begin{array}{l}\text { Gracias a la ciencia y sus descubrimientos nuestro esta- } \\
\text { do de bienestar mejora diariamente. }\end{array}$ & & & & & \\
\hline 5 & $\begin{array}{l}\text { Para poder sacar una buena nota en el examen de Físi- } \\
\text { ca basta con aprenderme de memoria unos conceptos } \\
\text { y unas fórmulas con el único objetivo de tener que re- } \\
\text { producirlos. }\end{array}$ & & & & & \\
\hline 6 & $\begin{array}{l}\text { Enseñar ciencias naturales es impartir conocimientos } \\
\text { que previamente ya han sido investigados y aceptados, } \\
\text { basta con mostrar fórmulas y comprobar leyes. }\end{array}$ & & & & & \\
\hline 7 & $\begin{array}{l}\text { El conocimiento científico es un cúmulo de datos ob- } \\
\text { jetivos que describen la realidad existente, interpre- } \\
\text { tándola de forma mecánica y sin necesidad de una } \\
\text { reflexión personal. }\end{array}$ & & & & & \\
\hline 8 & $\begin{array}{l}\text { Durante el aprendizaje en la asignatura de Física he } \\
\text { comprendido que los conceptos y las fórmulas no son } \\
\text { verdades aisladas, sino nociones provisionales e inte- } \\
\text { rrelacionadas entre ellas y aplicables a otros campos } \\
\text { del conocimiento. }\end{array}$ & & & & & \\
\hline 9 & $\begin{array}{l}\text { Sólo los alumnos de primaria que tengan habilidades } \\
\text { para ir por la rama científica son los que deberían es- } \\
\text { tudiar ciencia con mucha dedicación y entusiasmo, el } \\
\text { resto de los alumnos no necesitarán estos conceptos } \\
\text { en sus vidas. }\end{array}$ & & & & & \\
\hline 10 & $\begin{array}{l}\text { La ciencia es un conocimiento cierto, exacto y estático } \\
\text { de la naturaleza. }\end{array}$ & & & & & \\
\hline 11 & $\begin{array}{l}\text { La asignatura de Física trata fenómenos y problemas } \\
\text { alejados de la realidad. }\end{array}$ & & & & & \\
\hline 12 & $\begin{array}{l}\text { El aprendizaje de conocimientos científicos en primaria } \\
\text { debe ser un proceso activo por parte del alumno, cons- } \\
\text { truyendo los conceptos desde su propia perspectiva y } \\
\text { siendo capaz de progresar por sí mismo. }\end{array}$ & & & & & \\
\hline 13 & $\begin{array}{l}\text { No creo que los avances científicos ayuden a mejorar } \\
\text { mi vida cotidiana. }\end{array}$ & & & & & \\
\hline
\end{tabular}




\begin{tabular}{|c|c|c|c|c|c|c|}
\hline & ENUNCIADOS & $\begin{array}{l}\text { Totalmente } \\
\text { desacuerdo }\end{array}$ & $\begin{array}{c}\text { Parcialmente } \\
\text { desacuerdo }\end{array}$ & $\begin{array}{c}\text { No estoy } \\
\text { seguro }\end{array}$ & $\begin{array}{c}\text { Parcialmente } \\
\text { acuerdo }\end{array}$ & $\begin{array}{c}\text { Totalmente } \\
\text { acuerdo }\end{array}$ \\
\hline 14 & $\begin{array}{l}\text { La mejor manera de aprobar la asignatura de Física es } \\
\text { comprendiendo los conceptos y no estudiándolos de } \\
\text { memoria. }\end{array}$ & & & & & \\
\hline 15 & $\begin{array}{l}\text { Enseñar ciencias naturales significa que el niño com- } \\
\text { prenda y verifique sus experiencias cotidianas y no que } \\
\text { aprenda conceptos preestablecidos sin contextualizar. }\end{array}$ & & & & & \\
\hline 16 & $\begin{array}{l}\text { Lo importante de un saber científico no es conocer la } \\
\text { mayor cantidad posible de datos sin cuestionarlos, sino } \\
\text { desarrollar unas herramientas que te capaciten para } \\
\text { interpretar tu entorno y poder tomar decisiones cons- } \\
\text { cientes y responsables. }\end{array}$ & & & & & \\
\hline 17 & $\begin{array}{l}\text { La asignatura de Física es memorizar conceptos físicos } \\
\text { y fórmulas predeterminadas y fijas para aplicarlas para } \\
\text { la resolución de problemas poco significativos para mí. }\end{array}$ & & & & & \\
\hline 18 & $\begin{array}{l}\text { Cualquier alumno de primaria debería tener una alfa- } \\
\text { betización científica, puesto que de esta manera llega- } \\
\text { rán a ser personas más preparadas, críticas y con mejor } \\
\text { capacidad de tomar sus propias decisiones en su día } \\
\text { a día. }\end{array}$ & & & & & \\
\hline
\end{tabular}

COMPONENTE AFECTIVA

\begin{tabular}{|c|c|l|}
\hline VALORACIONES & CLAVE & \multicolumn{1}{|c|}{ Descripción de la valoración } \\
\hline Totalmente de acuerdo & TA & $\begin{array}{l}\text { Si compartes el contenido del enunciado tal y como está } \\
\text { redactado }\end{array}$ \\
\hline Parcialmente de acuerdo & PA & $\begin{array}{l}\text { Si compartes el contenido central del enunciado en } \\
\text { alguno aspectos }\end{array}$ \\
\hline No estoy seguro & N & Si estás indeciso con el enunciado \\
\hline Parcialmente en desacuerdo & PD & $\begin{array}{l}\text { Si no compartes el contenido central del enunciado, } \\
\text { aunque si estás de acuerdo con alguno de los aspectos }\end{array}$ \\
\hline Totalmente en desacuerdo & TD & $\begin{array}{l}\text { Si no compartes el contenido central del enunciado en } \\
\text { ninguno de sus aspectos. }\end{array}$ \\
\hline
\end{tabular}

\begin{tabular}{|c|c|c|c|c|c|c|}
\hline & ENUNCIADOS & $\begin{array}{l}\text { Totalmente } \\
\text { desacuerdo }\end{array}$ & $\begin{array}{c}\text { Parcialmente } \\
\text { desacuerdo }\end{array}$ & $\begin{array}{l}\text { No estoy } \\
\text { seguro }\end{array}$ & $\begin{array}{c}\text { Parcialmente } \\
\text { acuerdo }\end{array}$ & $\begin{array}{c}\text { Totalmente } \\
\text { acuerdo }\end{array}$ \\
\hline 19 & $\begin{array}{l}\text { Me entusiasma estar informado sobre los nuevos } \\
\text { avances de la ciencia. }\end{array}$ & & & & & \\
\hline 20 & $\begin{array}{l}\text { Siento indiferencia hacia las clases de Física puesto que } \\
\text { no les veo utilidad para vida. }\end{array}$ & & & & & \\
\hline 21 & $\begin{array}{l}\text { Me preocupa el hecho de que no pueda seguir un libro } \\
\text { de texto cuando tenga que impartir clases de ciencias, } \\
\text { ya que no tendré control ni de la información que les } \\
\text { transmita, ni de las posibles preguntas de los alumnos. }\end{array}$ & & & & & \\
\hline 22 & $\begin{array}{l}\text { Me divierte todo lo relacionado con la ciencia ya que } \\
\text { me ayuda a entender mejor cómo funciona el mundo. }\end{array}$ & & & & & \\
\hline 23 & $\begin{array}{l}\text { Me produce ansiedad el hecho de tener que razonar } \\
\text { para comprender los fenómenos y los conceptos físicos } \\
\text { con el fin resolver los problemas. }\end{array}$ & & & & & \\
\hline 24 & $\begin{array}{l}\text { Me alegra poder enseñar a mis alumnos debatiendo } \\
\text { con ellos sobre los conceptos científicos, animándoles } \\
\text { a buscar respuestas por distintos caminos para que } \\
\text { comprendan que algunas serán provisionales y/o mo- } \\
\text { dificables. }\end{array}$ & & & & & \\
\hline 25 & $\begin{array}{l}\text { La ciencia hace que me sienta orgulloso al capacitarme } \\
\text { para interpretar la realidad asignándole propiedades } \\
\text { que construyo yo mismo, lo que provoca que cambie } \\
\text { mi forma de pensar y mis costumbres. }\end{array}$ & & & & & \\
\hline
\end{tabular}




\begin{tabular}{|c|c|c|c|c|c|c|}
\hline & ENUNCIADOS & $\begin{array}{l}\text { Totalmente } \\
\text { desacuerdo }\end{array}$ & $\begin{array}{r}\text { Parcialmente } \\
\text { desacuerdo }\end{array}$ & $\begin{array}{l}\text { No estoy } \\
\text { seguro }\end{array}$ & $\begin{array}{c}\text { Parcialmente } \\
\text { acuerdo }\end{array}$ & $\begin{array}{l}\text { Totalmente } \\
\text { acuerdo }\end{array}$ \\
\hline 26 & $\begin{array}{l}\text { Me suele apetecer estudiar Física porque, no solo com- } \\
\text { prendo los conceptos y fenómenos básicos, sino que } \\
\text { además como los aplicamos en contextos significativos } \\
\text { y me ayudan a entender y a estar al tanto de las nove- } \\
\text { dades. }\end{array}$ & & & & & \\
\hline 27 & $\begin{array}{l}\text { Es desagradable saber que los conceptos científicos } \\
\text { que se enseñan en primaria no sean aplicables en la } \\
\text { vida real. }\end{array}$ & & & & & \\
\hline 28 & $\begin{array}{l}\text { Siento total apatía por estar al tanto de los nuevos des- } \\
\text { cubrimientos de la ciencia. }\end{array}$ & & & & & \\
\hline 29 & $\begin{array}{l}\text { Suelen sorprenderme las clases de Física ya que gracias } \\
\text { a ella comprendo fenómenos que observo o siento a } \\
\text { diario y que antes no sabía el porqué de estos. }\end{array}$ & & & & & \\
\hline 30 & $\begin{array}{l}\text { Me alivia saber que tengo la capacidad para enseñar } \\
\text { Ciencia proponiendo debates y entornos de aprendiza- } \\
\text { je significativos, sin utilizar el libro de texto. }\end{array}$ & & & & & \\
\hline 31 & $\begin{array}{l}\text { Me aburro solo de pensar en ciencia, total a mí no me } \\
\text { sirve para nada. }\end{array}$ & & & & & \\
\hline 32 & $\begin{array}{l}\text { Me siento más tranquilo comprendiendo los concep- } \\
\text { tos de Física para poder aplicarlos, sin necesidad de } \\
\text { estudiarme todo de memoria. }\end{array}$ & & & & & \\
\hline 33 & $\begin{array}{l}\text { Me deprime tener que enseñar ciencias por monótona } \\
\text { ya que es un conjunto de conceptos fijos preestablecidos }\end{array}$ & & & & & \\
\hline 34 & $\begin{array}{l}\text { Es frustrante percatarse de que tener conocimientos } \\
\text { científicos no me aporta nada, ya que son conceptos } \\
\text { aislados, tediosos y monótonos. }\end{array}$ & & & & & \\
\hline 35 & $\begin{array}{l}\text { Siento rechazo cuando tengo que estudiar algún tema } \\
\text { relacionado con la Física porque siempre se estudia lo } \\
\text { mismo, de la misma forma y sin ningún sentido. }\end{array}$ & & & & & \\
\hline 36 & $\begin{array}{l}\text { Es gratificante saber que los contenidos científicos que } \\
\text { imparten en primaria, ayudan a solucionar problemas } \\
\text { de la vida cotidiana. }\end{array}$ & & & & & \\
\hline
\end{tabular}

CONDUCTUAL

\begin{tabular}{|c|c|l|}
\hline VALORACIONES & CLAVE & \multicolumn{1}{|c|}{ Descripción de la valoración } \\
\hline Totalmente de acuerdo & TA & $\begin{array}{l}\text { Si compartes el contenido del enunciado tal y como está } \\
\text { redactado }\end{array}$ \\
\hline Parcialmente de acuerdo & PA & $\begin{array}{l}\text { Si compartes el contenido central del enunciado en } \\
\text { alguno aspectos }\end{array}$ \\
\hline No estoy seguro & N & Si estás indeciso con el enunciado \\
\hline Parcialmente en desacuerdo & PD & $\begin{array}{l}\text { Si no compartes el contenido central del enunciado, } \\
\text { aunque si estás de acuerdo con alguno de los aspectos }\end{array}$ \\
\hline Totalmente en desacuerdo & TD & $\begin{array}{l}\text { Si no compartes el contenido central del enunciado en } \\
\text { ninguno de sus aspectos. }\end{array}$ \\
\hline
\end{tabular}

\begin{tabular}{|c|c|c|c|c|c|c|}
\hline & ENUNCIADOS & $\begin{array}{l}\text { Totalmente } \\
\text { desacuerdo }\end{array}$ & $\begin{array}{l}\text { Parcialmente } \\
\text { desacuerdo }\end{array}$ & $\begin{array}{l}\text { No estoy } \\
\text { seguro }\end{array}$ & $\begin{array}{c}\text { Parcialmente } \\
\text { acuerdo }\end{array}$ & $\begin{array}{l}\text { Totalmente } \\
\text { acuerdo }\end{array}$ \\
\hline 37 & $\begin{array}{l}\text { En pocas ocasiones me apetece ver un documental } \\
\text { científico. }\end{array}$ & & & & & \\
\hline 38 & $\begin{array}{l}\text { Normalmente desconecto en la clase de Física. Apro- } \\
\text { barla es un mero trámite en mi carrera. }\end{array}$ & & & & & \\
\hline 39 & $\begin{array}{l}\text { Como profesional, involucraré a mis alumnos en un } \\
\text { aprendizaje por indagación de tal forma que formulen } \\
\text { sus propias hipótesis a partir de sus experiencias pre- } \\
\text { vias y las pongan a prueba para su contrastación. }\end{array}$ & & & & & \\
\hline
\end{tabular}




\begin{tabular}{|c|c|c|c|c|c|c|}
\hline & ENUNCIADOS & $\begin{array}{l}\text { Totalmente } \\
\text { desacuerdo }\end{array}$ & $\begin{array}{c}\text { Parcialmente } \\
\text { desacuerdo }\end{array}$ & $\begin{array}{l}\text { No estoy } \\
\text { seguro }\end{array}$ & $\begin{array}{c}\text { Parcialmente } \\
\text { acuerdo }\end{array}$ & $\begin{array}{l}\text { Totalmente } \\
\text { acuerdo }\end{array}$ \\
\hline 40 & $\begin{array}{l}\text { Promuevo en mi entono el gusto y el conocimiento por } \\
\text { la ciencia, sus avances y su utilidad en nuestras vidas. }\end{array}$ & & & & & \\
\hline 41 & $\begin{array}{l}\text { En las horas de clase procuro participar en los discusio- } \\
\text { nes que propone el profesor de Física, argumentando } \\
\text { mis opiniones, para apropiarme de los conceptos de tal } \\
\text { modo que sean significativos para mí. }\end{array}$ & & & & & \\
\hline 42 & $\begin{array}{l}\text { Cuando sea profesor, explicaré las leyes invariables y } \\
\text { las fórmulas ya comprobadas por otros y que los alum- } \\
\text { nos se las aprendan de memoria para resolver los pro- } \\
\text { blemas planteados. }\end{array}$ & & & & & \\
\hline 43 & $\begin{array}{l}\text { Observo y analizo mi entorno, esto hace que me sur- } \\
\text { jan preguntas a las que trato de dar respuesta como } \\
\text { hacen los científicos sin asumir, ni lo establecido, ni el } \\
\text { sentido común. }\end{array}$ & & & & & \\
\hline 44 & $\begin{array}{l}\text { La clase de Física no está para hablar sobre temas } \\
\text { científicos recientes, sino solo para aprender lo pre-es- } \\
\text { tablecido en el temario. }\end{array}$ & & & & & \\
\hline 45 & $\begin{array}{l}\text { Considero que, cuando sea profesor, impartiré las dis- } \\
\text { tintas materias de forma aislada sin tener en cuenta } \\
\text { que la integración de estás con la ciencia ayudarán a } \\
\text { una formación completa del alumno haciéndolo más } \\
\text { competente para la vida. }\end{array}$ & & & & & \\
\hline 46 & $\begin{array}{l}\text { De vez en cuando, me gusta leer una revista de cien- } \\
\text { cias o ver un documental para estar al tanto de los nue- } \\
\text { vos avances. }\end{array}$ & & & & & \\
\hline 47 & $\begin{array}{l}\text { Durante la clase de Física presto la máxima atención } \\
\text { puesto que lo aprendido y comprendido irá en mi pro- } \\
\text { pio beneficio al poder aplicarlo en mi vida profesional. }\end{array}$ & & & & & \\
\hline 48 & $\begin{array}{l}\text { Con mis alumnos de primaria, usaré una estrategia } \\
\text { doctrinal, donde el alumno asumirá un rol pasivo, } \\
\text { transmitiéndoles la máxima cantidad de temario sin } \\
\text { darles lugar ni a conocer ni a debatir sus ideas previas. }\end{array}$ & & & & & \\
\hline 49 & $\begin{array}{l}\text { No suelo motivar el acercamiento hacia ciencia entre } \\
\text { mi familia y amigos. }\end{array}$ & & & & & \\
\hline 50 & $\begin{array}{l}\text { Me desentiendo de los debates que surgen en la clase } \\
\text { de Física ya que lo único que me interesa es aprender } \\
\text { el máximo de conocimientos expuestos por el profesor } \\
\text { sin planteármelos. }\end{array}$ & & & & & \\
\hline 51 & $\begin{array}{l}\text { A la hora de elaborar mi propio material didáctico ten- } \\
\text { dré en cuenta los nuevos acontecimientos en relación } \\
\text { con la ciencia, de esta manera, podré incluir las nove- } \\
\text { dades y ampliar o modificar el contenido de las clases. }\end{array}$ & & & & & \\
\hline 52 & $\begin{array}{l}\text { No entra en mis planes resolver por mis propios me- } \\
\text { dios las dudas que me surgen sobre lo que ocurre a mi } \\
\text { alrededor, puesto que basta con buscar las respuestas } \\
\text { en internet. }\end{array}$ & & & & & \\
\hline 53 & $\begin{array}{l}\text { Como alumno, si me dieran la oportunidad, llevaría ar- } \\
\text { tículos de investigación científica a clase de Física para } \\
\text { comentar con mis compañeros algún hecho reciente } \\
\text { destacable. }\end{array}$ & & & & & \\
\hline 54 & $\begin{array}{l}\text { Si tengo oportunidad trabajaré conjuntamente todas } \\
\text { las materias para conseguir una alfabetización cientí- } \\
\text { fica, de tal forma que puedan utilizar lo aprendido en } \\
\text { su día a día. }\end{array}$ & & & & & \\
\hline
\end{tabular}




\section{ANEXO 3: Instrumento de elaboración propia para el análisis de las variables procedimentales}

\begin{tabular}{|c|c|c|c|}
\hline VARIABLE & INDICADOR & DESCRIPTOR & $\begin{array}{l}\text { NIVEL DE } \\
\text { PROGRESIÓN }\end{array}$ \\
\hline \multirow{4}{*}{$\begin{array}{l}\text { 1. Estrategia uti- } \\
\text { lizada. }\end{array}$} & Regla de tres & $\begin{array}{l}\text { Resuelve el problema mediante reglas de tres de } \\
\text { forma automatizada sin comprender el concepto } \\
\text { de proporcionalidad. }\end{array}$ & 1 \\
\hline & Tradicional & $\begin{array}{l}\text { Hace uso memorístico de las fórmulas matemá- } \\
\text { ticas. }\end{array}$ & II \\
\hline & $\begin{array}{l}\text { Registros de repre- } \\
\text { sentación pictográ- } \\
\text { ficos }\end{array}$ & $\begin{array}{l}\text { Utiliza registros de representación pictográficos } \\
\text { tanto con fines de comunicación como para un } \\
\text { desarrollo reflexivo del proceso de resolución. }\end{array}$ & III \\
\hline & $\begin{array}{l}\text { Factores } \\
\text { de conversión }\end{array}$ & $\begin{array}{l}\text { Aplica el concepto de proporcionalidad de mane- } \\
\text { ra razonada. }\end{array}$ & IV \\
\hline \multirow{4}{*}{$\begin{array}{l}\text { 2. Realización de } \\
\text { argumentaciones }\end{array}$} & Nunca & $\begin{array}{l}\text { Las argumentaciones realizadas no son adecua- } \\
\text { das. }\end{array}$ & 1 \\
\hline & Ocasionalmente & Algunas de las argumentaciones son adecuadas. & II \\
\hline & Habitualmente & $\begin{array}{l}\text { La mayoría de las argumentaciones son adecua- } \\
\text { das. }\end{array}$ & III \\
\hline & Siempre & $\begin{array}{l}\text { Todas las argumentaciones realizadas son ade- } \\
\text { cuadas. }\end{array}$ & IV \\
\hline \multirow{4}{*}{$\begin{array}{l}\text { 3. Validez de las } \\
\text { argumentaciones }\end{array}$} & Nunca & $\begin{array}{l}\text { Las argumentaciones realizadas no son adecua- } \\
\text { das. }\end{array}$ & 1 \\
\hline & Ocasionalmente & Algunas de las argumentaciones son adecuadas. & II \\
\hline & Habitualmente & $\begin{array}{l}\text { La mayoría de las argumentaciones son adecua- } \\
\text { da. }\end{array}$ & III \\
\hline & Siempre & $\begin{array}{l}\text { Todas las argumentaciones realizadas son ade- } \\
\text { cuadas. }\end{array}$ & IV \\
\hline \multirow{4}{*}{$\begin{array}{l}\text { 4. Uso de las uni- } \\
\text { dades de medida }\end{array}$} & Nunca & No hace uso de las unidades de medida. & 1 \\
\hline & Ocasionalmente & Escribe las unidades, pero solo en el resultado. & II \\
\hline & Habitualmente & $\begin{array}{l}\text { Habitualmente hace uso de las unidades de me- } \\
\text { dida. }\end{array}$ & III \\
\hline & Siempre & $\begin{array}{l}\text { Hace uso de las unidades de medida durante } \\
\text { todo el proceso. }\end{array}$ & IV \\
\hline \multirow{4}{*}{$\begin{array}{l}\text { 5. Validez en el } \\
\text { uso de las unida- } \\
\text { des de medida }\end{array}$} & Nunca & $\begin{array}{l}\text { Las unidades de medida utilizadas no son ade- } \\
\text { cuadas. }\end{array}$ & 1 \\
\hline & Ocasionalmente & $\begin{array}{l}\text { Algunas unidades de medida utilizadas son las } \\
\text { adecuadas }\end{array}$ & II \\
\hline & Habitualmente & $\begin{array}{l}\text { La mayoría de las unidades de medida utilizadas } \\
\text { son adecuadas. }\end{array}$ & III \\
\hline & Siempre & $\begin{array}{l}\text { Todas las unidades de medida utilizadas son ade- } \\
\text { cuadas. }\end{array}$ & IV \\
\hline
\end{tabular}




\section{ANEXO 4: Secuencia didáctica}

\section{Ejemplo de situaciones contextualizadas durante la secuencia de aprendizaje.}

Durante el proceso de enseñanza y aprendizaje de las distintas magnitudes relativas a la Cinemática se han utilizado varios contextos exponiendo al alumnado ante situaciones problemáticas que debían resolver partiendo desde sus ideas previas. Por ejemplo:

\section{- ¿Cómo influye en la velocidad del sonido el medio por el que viaja?}

1. Tenemos a cuatro personas en una piscina. Dos fuera del agua en extremos opuestos ( $A$ y $B$ ) y otras dos en los mismos puntos, pero bajo el agua ( $C$ y $D)$. Si los dos que están en el mismo extremo hacen sonar una bocina $(A$ y $C$ ) ¿Quién de las otras dos personas $(B \circ D)$ escuchará antes el sonido? ¿Por qué?

2. ¿Cómo influye esto a las deportistas de natación sincronizada?

3. ¿Podrías argumentar por qué en las películas del oeste los indios apoyaban la oreja en la vía del tren?

4. ¿Podrías encontrar otras situaciones en las que se pone de manifiesto las distintas velocidades del sonido en función del medio en el que se mueva?

5. ¿Cómo puede la ciencia aprovechar este fenómeno?

- ¿Qué diferencias hay entre la propagación del sonido y la de la luz?

1. ¿Cuál es la razón por la que vemos el relámpago antes de escuchar el trueno?

2. ¿Crees que este fenómeno ocurre también cuando vemos fuegos artificiales?

3. Si durante una tormenta oímos un trueno 4 segundos después de ver el relámpago. ¿Podemos averiguar de alguna manera a qué distancia se encuentra la tormenta?

4. ¿Cómo mediríais la velocidad del sonido? ¿Y la de la Luz?

5. Una vez trabajado en clase cómo lo hizo Galileo, buscad otros métodos por los que a lo largo de la historia se han realizado estas mediciones.
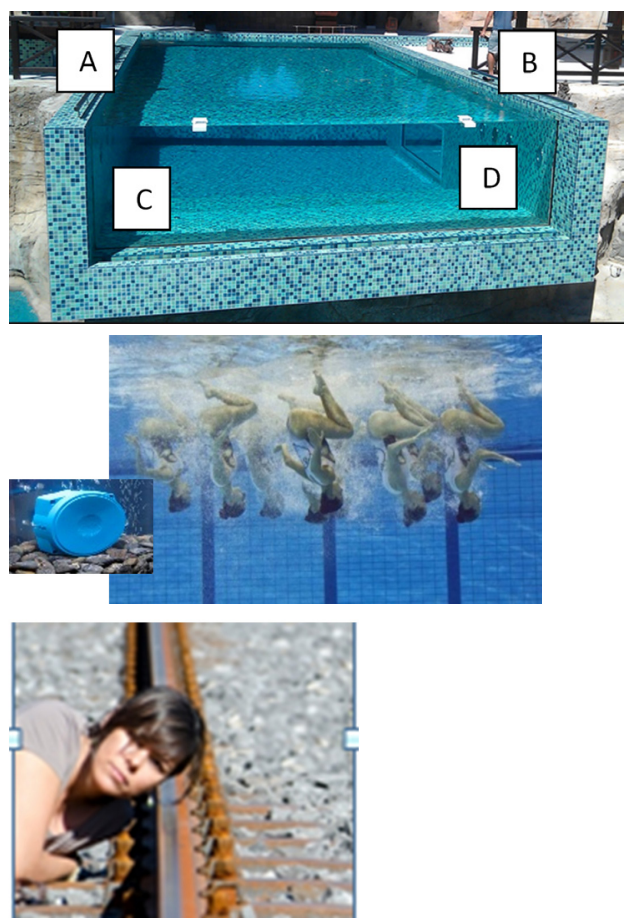

Velocidad de propagación del sonido en diferentes medios

\begin{tabular}{|c|c|}
\hline Medios & Velocidad $(\mathrm{m} / \mathbf{s})$ \\
\hline Aire & 330 \\
\hline Aire $(20 \circ \mathrm{C})$ & 340 \\
\hline Agua & 1450 \\
\hline Cobre & 3960 \\
\hline Hierro & 5100 \\
\hline Vidrio & 5500 \\
\hline
\end{tabular}

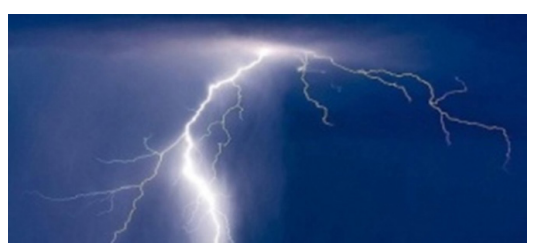

